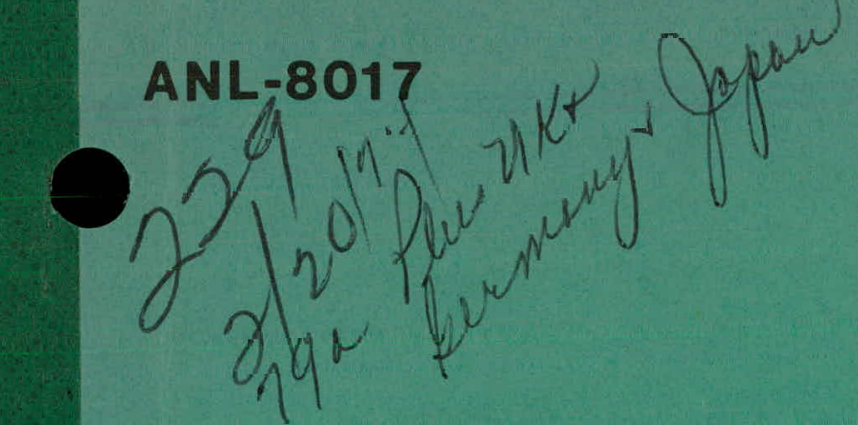

\title{
DETERMINATION OF CARBON IN SODIUM BY
}

TAB EQUILIBRATIONS AND BY CARBON METERS

AND

THE CARBURIZATION OF STAINLESS STEELS

IN SODIUM SYSTEMS

M. F. Roche, J. W. Allen,

R. J. Meyer, and F. A. Cafasso

BASE TECHNOLOGY

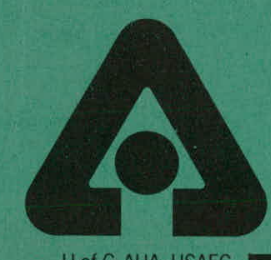

ARGONNE NATIONAL LABORATORY, ARGONNE, ILLINOIS

Prepared for the U.S. ATOMIC ENERGY COMMISSION Division of Reactor Research and Development 


\section{DISCLAIMER}

This report was prepared as an account of work sponsored by an agency of the United States Government. Neither the United States Government nor any agency Thereof, nor any of their employees, makes any warranty, express or implied, or assumes any legal liability or responsibility for the accuracy, completeness, or usefulness of any information, apparatus, product, or process disclosed, or represents that its use would not infringe privately owned rights. Reference herein to any specific commercial product, process, or service by trade name, trademark, manufacturer, or otherwise does not necessarily constitute or imply its endorsement, recommendation, or favoring by the United States Government or any agency thereof. The views and opinions of authors expressed herein do not necessarily state or reflect those of the United States Government or any agency thereof. 


\section{DISCLAIMER}

Portions of this document may be illegible in electronic image products. Images are produced from the best available original document. 
The facilities of Argonne National Laboratory are owned by the United States Government. Under the terms of a contract (W-3I-109-Eng-38) between the U. S. Atomic Energy Commission, Argonne Universities Association and The University of Chicago, the University employs the staff and operates the Laboratory in accordance with policies and programs formulated, approved and reviewed by the Association.

\section{MEMBERS OF ARGONNE UNIVERSITIES ASSOCIATION}

The University of Arizona Carnegie-Mellon University Case Western Keserve Unives sily The University of Chicago

University of Cincinnati Illinois Institute of Technology University of Illinois Indiana University Iowa State University The University of lowa
Iransas State University The University of Kansas Loyola Univarsity Marquelle Univel sity Ivllehigan State Univoraity The University of Michigan University of Minnesota University of Missouri Northwestern University Univeroity of Nintre Dame
The Ohio State University Ohio University

The Pennsylvania State University Purdine Inniversity

Saint Louis University Southern Illinois University The University of Texas at Austin Washington University Wayne State Unlversily The University of Wisconsin

\section{NOTICE}

Thlu rupush wa.a propnorod as an arrnint of work sponsored by the United States Government. Neither the United States nor the United States Atomic Energy Commission, nor any of their employees, nor any of their contractors, subcontractors, or their employees, makes any warranty, express or implied, or assumes any legal liability or responsibility for the accuracy, completeness or usefulness of any information, apparatus, product or process disclosed, or represents that its use would not infringe privately-owned rights.

Printed in the United States of America

Available from

National Technical Information Service

U.S. Department of Commerce

5285 Port Royal Road

Springfield, Virginia 22151

Price: Printed Copy $\$ 4.00$; Microfiche $\$ 1.45$ 


\section{DETERMINATION OF CARBON IN SODIUM BY TAB EQUILIBRATIONS AND BY CARBON METERS}

AND

THE CARBURIZATION OF STAINLESS STEELS IN SODIUM SYSTEMS

by.

M. F. Roche, J.W. Allen, R. J. Meyer, and F. A. Cafasso

Chemical Engineering Division

$$
\text { NOTICE }
$$

This report was prepared as an account of work sponsored by the United States Government. Neither the United States nor the United States Atomic Enerky Cummlssion, nor any of their employees, not any .of their contractors, subcontractors, or their employees, makes any warranty, express or implied, or assumes any legal liability or responsibility for the accuracy, com. pleteness or usefulness of any information, apparatus, pleteness or usefuln sisclosed, or represents product or process disclosed, or represents. would not infringe privately owned rights. 


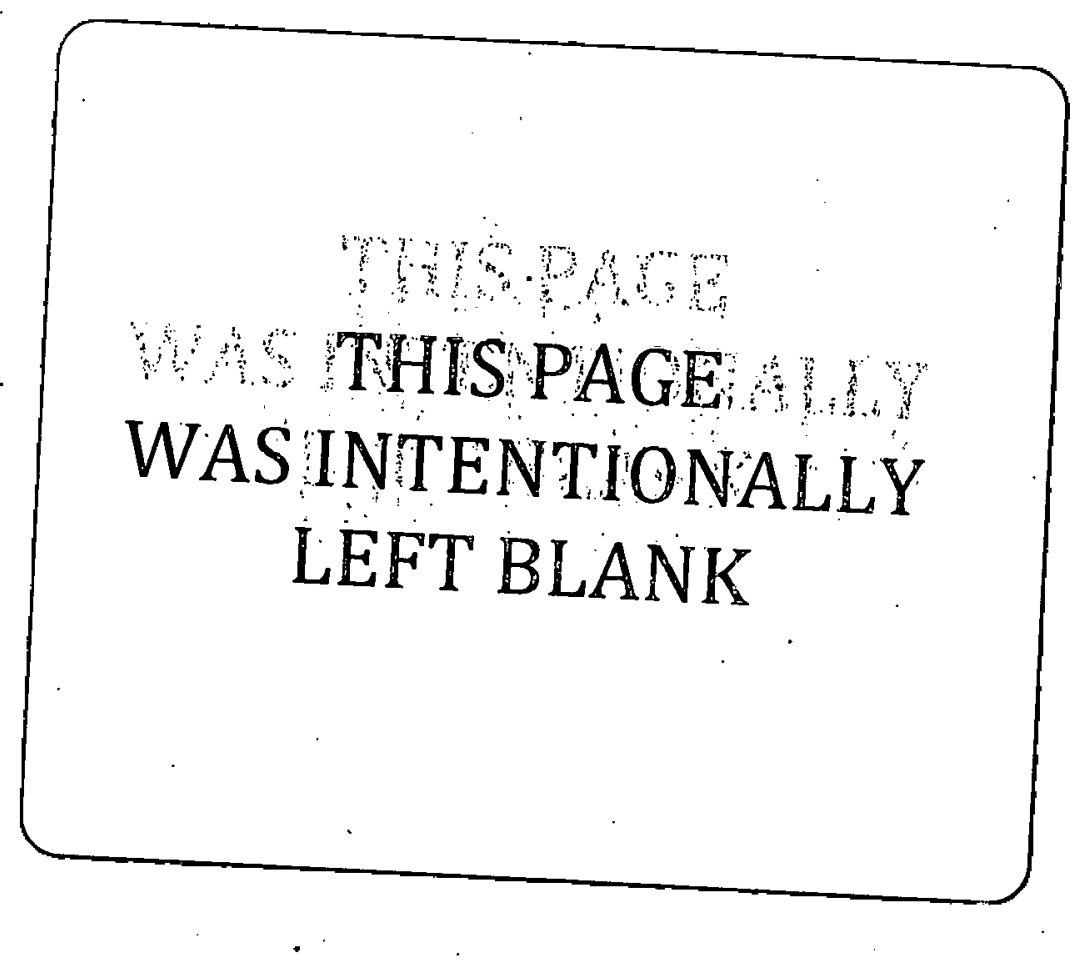

$\checkmark$

$$
\text { I }
$$


ABSTRACT. . . . . . . . . . . . . . . . . . . . . . . 1

I. INTRODUCTION . . . . . . . . . . . . . . . . . . . . 2

II. EXPERIMENTAL METHOD AND RESULTS . . .............. 5

III. DISCUSSION. • . . . . . . . . . . . . . . . . . . 17

A. Tab Materials : Fe-12 wt \% Mn and Fe-8 wt \% Ni... . . . . 17

B. Tab Materials: $\mathrm{Ta}, \mathrm{Zr}, \mathrm{Co}, \mathrm{Ti}, \mathrm{V}$, and Mo . . . . . . . 21

C. Response of Diffusion-type Meters to Carbon in Sodium . . . $\quad 22$

D. Response of Stainless Steels to Carbon in Sodium. . . . . 28

E. Response of Electrochemical Meters to Carbon in Sodium. . . 33

F. Response of ANL Pressure-type 'Carbon Meter to Carbon

in Sodium . . . . . . . . . . . . . . . . . . 35

IV. CONCLUSIONS . . . . . . . . . . . . . . . . . . 39

ACKNOWLEDGMENTS . . . . . . . . . . . . . . . . . . . . . 39

REFERENCES. . . . . . . . . . . . . . . . . . . . 4 40 


\section{LIST OF FIGURES}

No.

1. Glovebox Equipped with Furnace Wells for Use in Pot-type

Experiments ..........................

2. Diffusion-type Carbon Meter, Shown as Used in a Pot-type

Experiment.

3. Brookhaven National Laboratory Electrochemical Carbon Meter . . 7

4. Argonne National Laboratory Electrochemical Carbon Meter. . . . 7

5. Argonne National Laboratory Pressure-type Carbon Meter... . . . 8

6. Carbon Concentration in Fe-12 wt \% Mn Tabs, Expressed as $\mathrm{N}_{\mathrm{c}} /\left(1-5 \mathrm{~N}_{\mathrm{c}}\right)$, as a Function of Carbon Activity. . . . . . . . .

7. Carbon Concentration in Ti, V, and Mo Tabs, Expressed as $\mathrm{N}_{c} /\left(1-5 \mathrm{~N}_{c}\right)$, as a Function of Carbon Activity. . . . . . . .

8. Response of UNC and High-Area Diffusion-type Carbon Meters to Carbon in Sodium at $700^{\circ} \mathrm{C}$. . . . . . . . . . . . . . 22

9. Effect of Stirrer Speed on Carbon Flux Through the Diffusiontype Carbon Meters. .. . . . . . . . . . . . . . . . .

1.0. High-area Diffusion Meter Reading: Measurement of Stirrerspeed Effect..........................

11. Comparison of Carbon Concentration in Types 304 and 321 Stainless Steel after their Simultaneous Exposure to $700^{\circ} \mathrm{C}$ Sodium. . .

12. Comparison of Response of Type 304 Stainless Steel Tabs and Diffusion-type Carbon Meters in $700^{\circ} \mathrm{C}$ Sodium. . . . . . . . . .

13. Approximately Linear Relationship Between Type 304 Stainless Steel Carburization and UNC Meter Reading ...........

14. Comparison of (1) Measured Response of BNL Meter to Carbon in $700^{\circ} \mathrm{C}$ Sodium;

(2) Predicted Response from Ref. 7. . . . . . 


\section{LIST OF TABLES}

No.

I. Characteristics of Experimental Tab Materials. . . . . . . . . 9

II. Composition of Alloys. . . . . . . . . . . . . . . 10

III. Carbon Concentration in Tab Materials and Carbon Meter

Readings in $700^{\circ} \mathrm{C}$ Sodium . . . . . . . . . . . . . 11

Ty, Carbon Activity in $700^{\circ} \mathrm{C}$ sodium as Determined by Fe-8 wt \% Ni and by $\mathrm{Ni}$ Tabs . . . . . . . . . . . . . . . . . .

V. Carbon Activity in $750^{\circ} \mathrm{C}$. Sodium as Determined by $\mathrm{Fe}-8$ wt \% $\mathrm{Ni}$ and $\mathrm{Fe}-12$ wt \% Mn Tabs . . . . . . . . . . . . . . . . 20

VI. Experiments with ANL Electrochemical Carbon Meter. . .. . . . . 35

VII. Experiments with ANL Pressure-type Carbon Meter. . . . . . . . . 37 


\author{
DETERMINATION OF CARBON IN SODIUM BY \\ TAB EQUILIBRATIONS AND BY .CARBON METERS \\ AND \\ THE CARBURIZATION OF STAINLESS STEELS IN SODIUM SYSTEMS
}

by

M. F. Roche, J. W. Allen, R. J. Meyer, and F. A. Cafasso

\title{
ABSTRACT
}

A method of determining carbon activity in sodium using $\mathrm{Fe}-12$ wt $\%$ Mn tabs has been developed and tested over a range of carbon activities extending from 0.002 to 0.3 in $700^{\circ} \mathrm{C}$ sodium. The method was used to measure the carbon activity in sodium-filled, stainless steel loops and in the EBR-II reactor. The carbon activity at $700^{\circ} \mathrm{C}$ in EBR-II sodium was found to be $2.2 \times 10^{-3}$.

In addition, the response of carbon meters and the carburization of stainless steels were studied using the tab method. Two carbon meters, a recently developed electrochemical meter and a pressure meter, were found to give measurements of carbon activity that were in good agreement with the values obtained using the $\mathrm{Fe}-12$ wt \% Mn tab method. Further development of these two meters for use as on-line monitors of carbon in sodium systems is recommended. It was found that the carburization of Type 304 stainless steel was dependent on sodium flow conditions, and, that the carburization varied as the square of the carbon activity ( $a^{2}$ ) for fixed flow conditions. The $a_{c}^{2}$ dependence suggests that the major carbon species in sodium is disodium acetylide. Diffusion meters were found to give a response to carbon in sodium that parallels the carburization behavior of Type 304 stainless steel. Consequently, the diffusion meters are expected to be useful tools in steel carburization studies. 


\section{INTRODUCTION}

The carburization and decarburization of stainless steels in contact with high-temperature sodium, and the associated detrimental effects on their mechanical properties, may play an important role in determining the useful life of some of the components of sodium-cooled fast-breeder reactors. Studies of the mechanism and kinetics of these carburization and decarburization phenomena have been hampered because conventional methods for determining carbon in sodium have been inadequate. A tab-equilibration method for determining carbon activity, based on the use of austenitic $\mathrm{Fe}-\mathrm{Ni}$ alloys, has been proposed ${ }^{1,2}$ to fill this need. According to the proposed method, carbon activity in the sodium is measured in a manner analogous to the recently developed vanadium-wire equilibration method for determining oxygen activity in sodium. 3

The tab-equilibration method of measuring the activity of carbon in sodium is based on simple thermodynamic considerations. When an appropriate metal tab is placed in sodium containing carbon, carbon diffuses between the sodium and the tab material until, at equilibrium, the chemical potentials of carbon in the tab and in the sodium are identical. This equilibration is essentially complete within a period of three days at a temperature of $700^{\circ} \mathrm{C}$ for 5-mil-thick tabs of either Fe-12 wt \% Mn or Fe-8 wt \% $\mathrm{Ni}$. (The method using $\mathrm{Fe}-12$ wt \% Mn tabs was developed and tested in this study.) When the same standard state is chosen for carbon in the sodium and in the tab, the activity exhibited by dissolved carbon is the same in the sodium and the tab material at equilibrium, as can be seen from the following equations:

$$
\begin{aligned}
& \mu_{\mathrm{Na}}^{c}=\mu_{0}^{c}+R T \cdot \ln a_{\mathrm{Na}}^{c} \\
& \mu_{\mathrm{tab}}^{c}=\mu_{0}^{c}+R T \ln a_{\mathrm{tab}}^{\mathrm{c}} \\
& \mu_{\mathrm{Na}}^{\mathrm{c}}=\mu_{\mathrm{tab}}^{c} \text { (at equilibrium) }
\end{aligned}
$$

where

$$
\begin{aligned}
& \mu_{\mathrm{Na}}^{\mathrm{c}}, \mu_{\mathrm{Lab}}^{\mathrm{c}}=\text { the chemical potential of the dissolved carbon } \\
& \mu_{0}^{c}=\text { the chemical potential of carbon in the chosen } \\
& \text { standard state } \\
& \mathrm{a}_{\mathrm{Na}}^{\mathrm{c}}, \mathrm{a}_{\mathrm{tab}}^{\mathrm{c}}=\text { the activity of carbon, relative to the standard }
\end{aligned}
$$

Insertion of Eq. 1 and 2 in Eq. 3 leads to the result, $a_{\mathrm{Na}}^{c}=a_{\mathrm{tab}}^{\mathrm{c}}$. Thus, the activity of carbon in the sodium may be determined from a measurement of the concentration of carbon in an equilibrated tab and a knowledge of the function of carbon concentration $v s$. carbon activity for the tab material.

Graphite, for which $\mu_{0}^{c}$ is zero in the above equations, is chosen as a convenient standard state for carbon in both the sodium and tab material. Thus, sodium in equilibrium with graphite at a given temperature has a carbon 
activity of one. However, even this carbon-saturated solution contains very little carbon; the solubility of carbon in sodium at $700^{\circ} \mathrm{C}$, for instance, is only $8 \mathrm{ppm} .5$

In the tab-equilibration experiments reported here, the results have shown that sodium in typical stainless steel systems is far from being saturated with carbon. Carbon activities at $700^{\circ} \mathrm{C}$ in these systems were about $3 \times 10^{-3}$, corresponding to a carbon concentration in the sodium of only $0.07 \mathrm{ppb} . *$ Direct measurement of such low concentrations is beyond the capability of conventional methods, but a tab of Fe-12 wt \% $\mathrm{Mn}$, when equilibrated at $700^{\circ} \mathrm{C}$ with sodium at a carhnn astivity of $3 \times 10^{-3}$, has d sufficiently high carbon concentration (about $40 \mathrm{ppm} \mathrm{C}$ ) to permit a determination by combustion analysis. Thus, the tab method provides a convenient means of determining very low concentrations of carbon in sodium.

The objectives of this study were as follows:

1. Test the validity of the tab-equilibration method for determining carbon activity in sodium (previous studies $^{-1}$ have relied heavily on gas-mixture equilibrations).

2. Test tab materials having a higher carbon concentration than $\mathrm{Fe}-\mathrm{Ni}$ alloys at low carbon activities.

3. Determine the activity of carbon in sodium-steel systems by means of the tab-equilibration method.

4. Determine the factors controlling the rate of carburization of steels in high-temperature sodium.

5. Characterize the performance of existing carbon meters and develop and test new meters for the measurement of carbon in sodium.

Briefly, the results of this study were as follows:

1. It was demonstrated for selected tab materials that equilibration in sodium led to relationships of carbon activity vs. carbon concentration that were in agreement with those obtained by gasequilibration techniques.

2. An austenitic Fe-Mn alloy, $\mathrm{Fe}-12 \mathrm{wt} \% \mathrm{Mn}$, was found to have a carbon concentration, at a given activity, considerably higher than that in $\mathrm{Fe}-\mathrm{Ni}$ alloys. Consequently, $\mathrm{Fe}-12$ wt $\% \mathrm{Mn}$ has been chosen for use in determining the activity of carbon in sodium systems. 4

3. Stainless-steel sodium systems, including a number of sodium loops and the EBR-II reactor, were found to operate at low carbon activities, typically $10^{-2}$ to $10^{-3}$.

${ }^{\star}$ If the carbon is present only as disodium acetylide, $\mathrm{Na}_{2} \mathrm{C}_{2}$, the carbon concentration in the sodium will decrease as the square of the carbon activity, and, at a carbon activity of $3 \times 10^{-3}$, the carbon concentration will be $\left[8 \times\left(3 \times 10^{-3}\right)^{2}\right] \mathrm{ppm}$ or $0.07 \mathrm{ppb}$. 
4. The carburization rate of Type 304 stainless steel was found to be controlled by sodium flow conditions and by the reaction rate of carbon at the sodium-steel interface. For fixed flow conditions, the carburization rate varied as the square of the carbon activity, $a^{2}$, which suggests that the major species in sodium is disodium acetylide.

5. Three types of meters for measuring carbon in sodium were tested: diffusion, electrochemical and pressure meters. The principle of operation of each of these is described in the next section of this report. The United Nuclear Corporation (UNC) diffusion meter ${ }^{6}$ showed a response to carbon in sodium that paralleled the carburization behavior of Type 304. stainless steel. Consequently, this meter is a useful tool in steel carburization studies. The Brookhaven National Laboratory (BNL). electrochemical meter ${ }^{7}$ was found to have a poor response to carbon in sodium, particularly at carbon activities less than 0.1. An improved electrochemical meter 8 developed at Argonne National Laboratory (ANL) gave carbon activities, calculated from the meter emf, that were in good agreement with tab-equilibration measurements. A pressure meter developed in this study also gave carbon activities, calculated from the meter pressure, that were in good agreement with tab-equilibration measurements. The ANL electrochemical meter and the pressure meter are expected to be useful on-line monitors of carbon activity in sodium systems. 


\section{EXPERIMENTAL METHOD AND RESULTS}

Most of the experiments were conducted in a helium-atmosphere glovebox equipped with two furnace wells, as illustrated in Fig. 1. The glovebox atmosphere was continuously purified by circulation of the helium through a molecular-sieve trap cooled by liquid nitrogen. An assembly comprising a pot, baffles, and a stirrer, made of either Type 200 nickel or Type 304 stainless steel and containing about 1.5 liters of sodium, was placed in. each furnace well. A carbon meter and a thermocouple well containing a chromelalumel thermocouple extended through the baffles into the sodium.

The carbon meters tested at various times during this experimental program included two diffusion meters, two electrochemical meters, and one pressure meter. The diffusion meters ${ }^{6}$ were developed by UNC. One of the UNC meters differed from the other in that it had a larger membrane; this meter was called the high-area meter. The regular UNC meter had a $7.25 \mathrm{~cm}^{2}, 10$-milthick, Armco iron membrane, whereas the high-area meter had a $35 \mathrm{~cm}^{2}$, 5-milthick, high-purity iron membrane. A typical experimental arrangement in which a diffusion meter is used is shown in Fig. 2. Carbon in the hightemperature sodium reacts with the membrane of the diffusion meter at the iron-sodium interface and diffuses to the interior surface of the membrane, where the carbon reacts with a flowing, humidified, hydrogen-argon gas mixture to form carbon monoxide. (The gas mixtures were $0.7 \% \mathrm{H}_{2} \mathrm{O}, 5 \% \mathrm{H}_{2}$, balance argon for the UNC meter and $1.4 \% \mathrm{H}_{2} \mathrm{O}, 15 \% \mathrm{H}_{2}$, balance argon for the high-area meter.) The $\mathrm{CO}$ in the gas stream is transported to a catalytic converter, where it is converted to methane; the methane is measured continuously by a flame ionization detector (FID). Background readings of 150 to 300 FID units, due mainly to impurities in the gas mixture, were measured and subtracted from the observed readings.

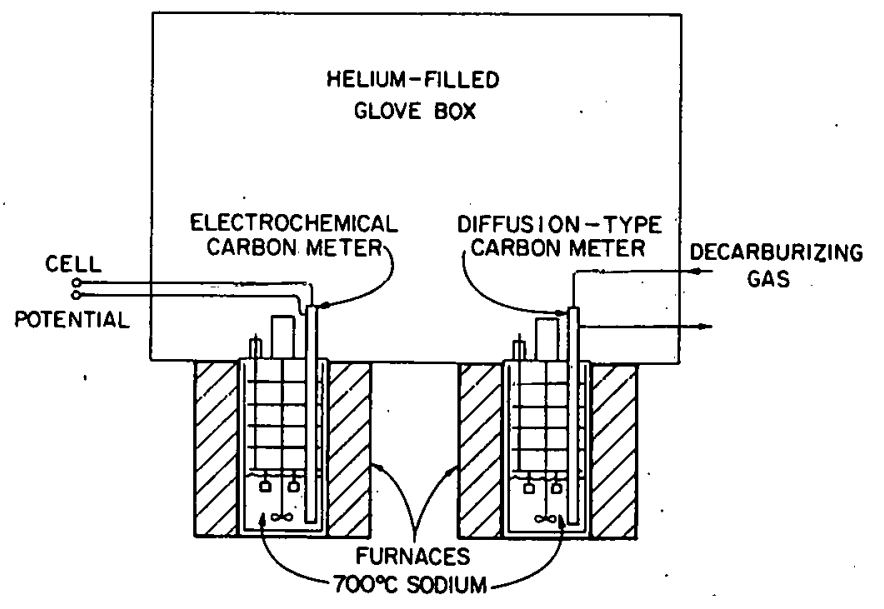

Fig. 1. Glovebox Equipped with Furnace Wells for Use in Pot-type Experiments 


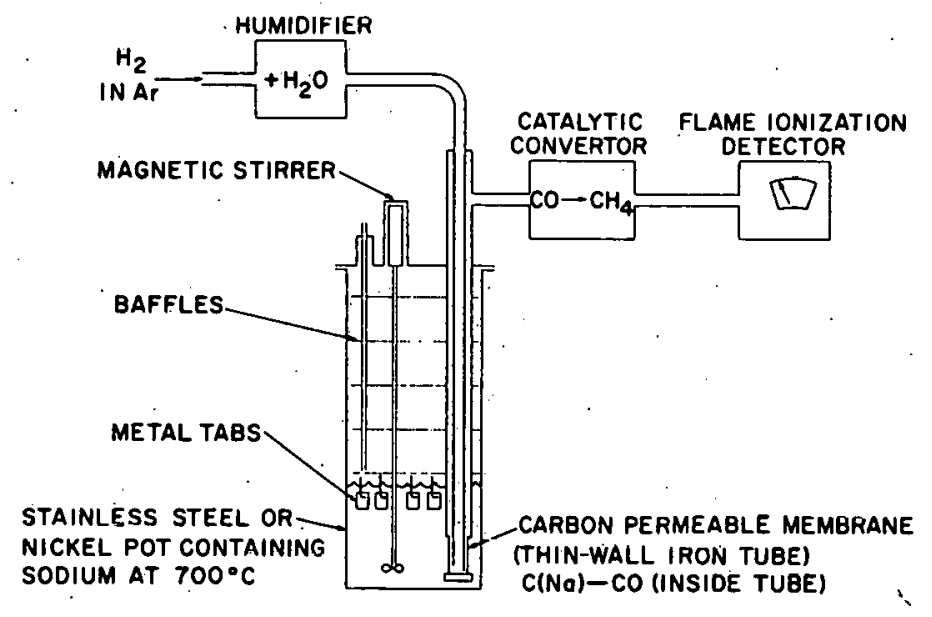

Fig. 2. Diffusion-type Carbon Meter, Shown as Used in a Pot-type Experiment. (The pot is 15 in. long by 5 -in. OD.)

The Brookhaven National Laboratory electrochemical carbon meter ${ }^{7}$, shown in Fig. 3, consists of a thin-walled iron cup containing a $\mathrm{Na}_{2} \mathrm{CO}_{3}-\mathrm{Li}_{2} \mathrm{CO}_{3}$ eutectic mixture and a graphite reforence electrode. The difference in potential between the iron cup and the graphite is expected to be equal to $\frac{\mathrm{RT}}{4 \mathrm{~F}}$ In $a_{c}$, where $a_{c}$ is the carbon activity in the sodium.

The Argonne National Laboratory electrochemical meter ${ }^{8}$ (see Fig. 4) consists of (1) a tin-tin oxide reference electrode within a zirconia/calcia electrolyte tube that is platinized on its external surface and is evacuated and sealed, (2) a surrounding gas space that is filled to 2 Torr with a mixture of $\mathrm{CO}(66 \%)$ and $\mathrm{CO}_{2}(34 \%)$, and (3) an iron cylinder with a 10-mil-thick wall in which the gas mixture and reference electrode are confined. On immersion of this meter in $700^{\circ} \mathrm{C}$ sodium, carbon diffuses through the iron and adjusts the $\mathrm{CO}_{2} / \mathrm{CO}$ ratio to satisfy the equilibrium $\mathrm{CO}_{2}+\mathrm{C} \stackrel{\leftarrow}{\rightarrow} \mathrm{CO} ; \mathrm{P}_{\mathrm{CO}}+$ $\mathrm{P}_{\mathrm{CO}_{2}}=2$ Torr. As the reaction proceeds, minor adjustments in pressure are made to maintain a pressure of 2 Torr. The difference in oxygen activity between the $\mathrm{CO}_{2} / \mathrm{CO}$ mixture and the $\mathrm{Sn} / \mathrm{SnO}_{2}$ reference electrode gives rise to a difference in potential that is sensed by a high-impedance millivoltmeter. The carbon activity is a calculable function of this potential.

The Argonne National Laboratory pressure meter, shown in Fig. 5, consists of an iron capsule having an annular design (for high area and small volume) and a capacitance-type electronic manometer that is connected to the capsule by copper tubing. Copper is chosen for its low reactivity with $\mathrm{CO} / \mathrm{CO}_{2} \mathrm{mix}-$ tures. The copper is protected from exposure to sodium or air by an argonfilled, cold-rolled steel tube. Carbon diffuses from the sodium through the wall of the previously evacuated capsule and reacts at the interior surface 


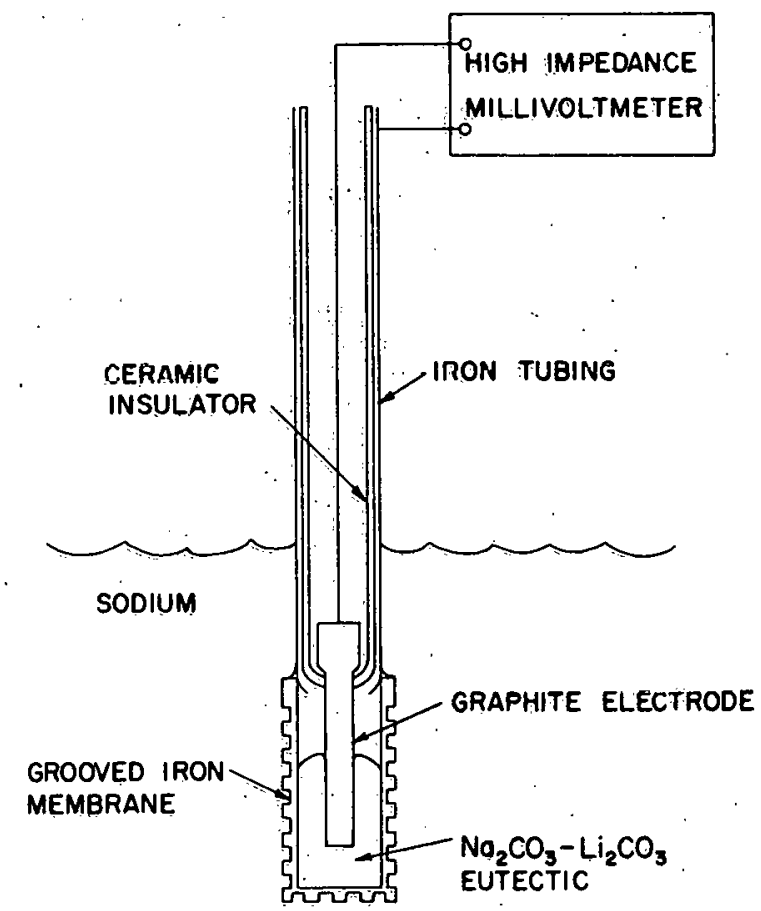

Fig. 3. Brookhaven National Laboratory Electrochemical Carbon Meter. (Iron membrane is 0.5 -in. ID by 3 in. long.)

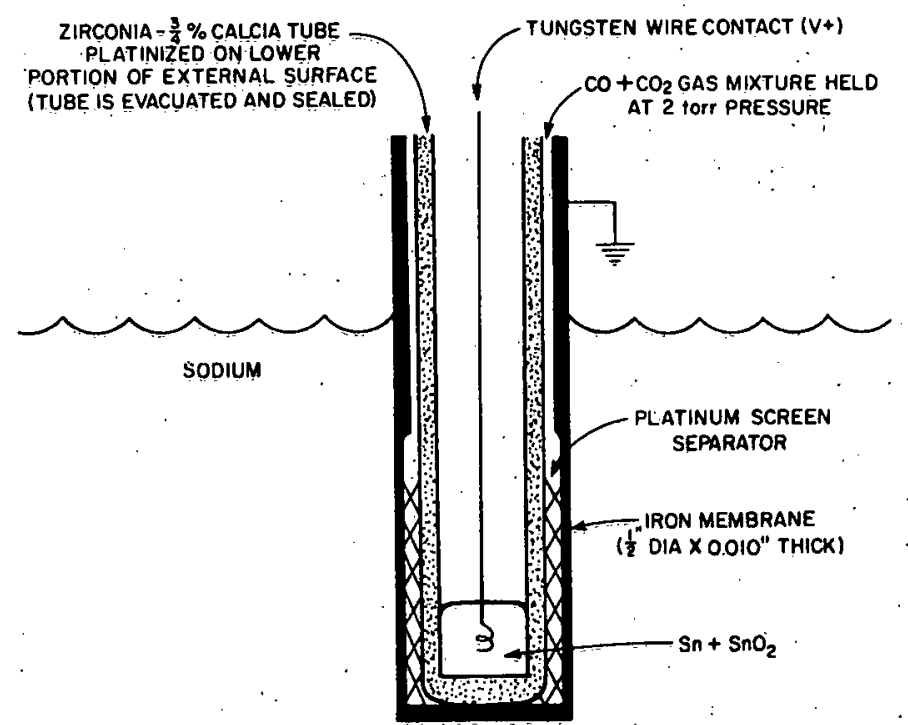

Fig. 4. Argonne National Laboratory Electrochemical Carbon Meter 


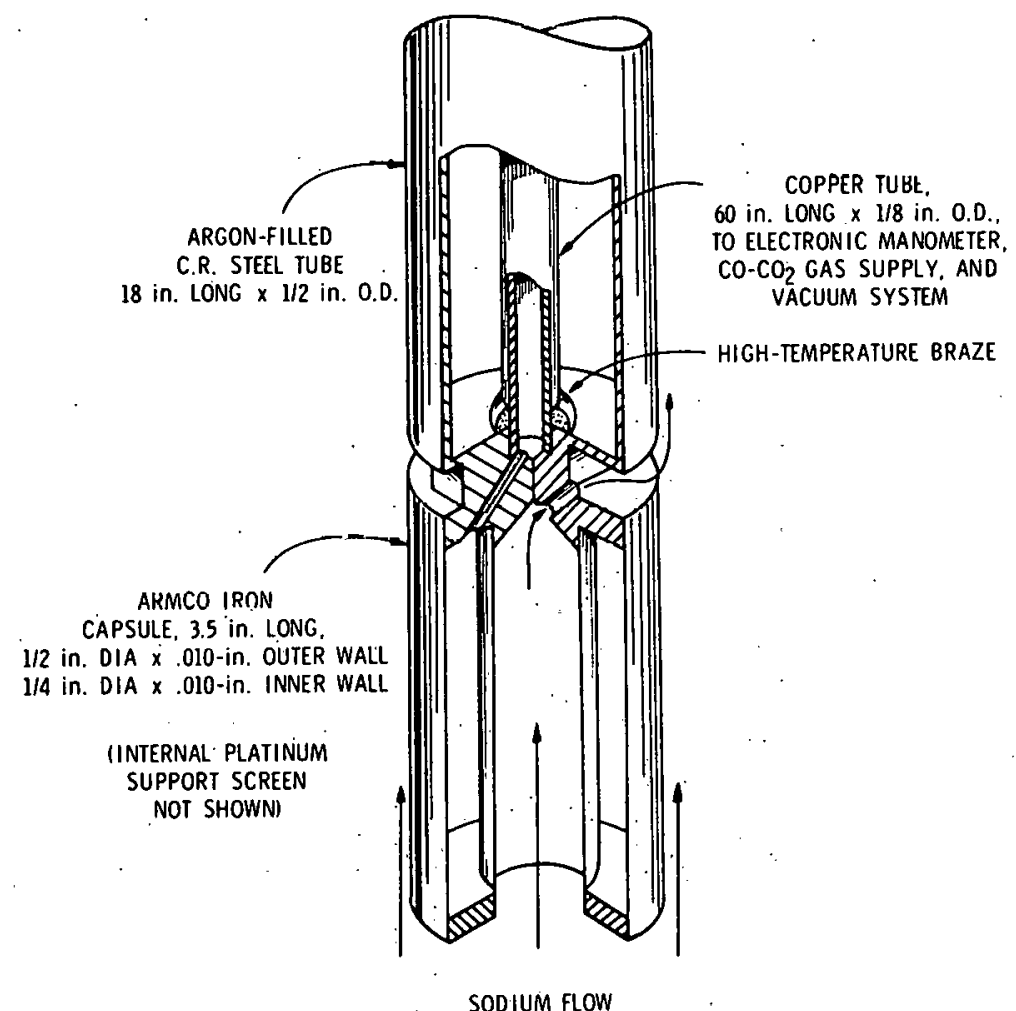

Fig. 5. Argonne National Laboratory PressureType Carbon Meter

with a layer of wustite $\left(\mathrm{Fe}_{0.947} \mathrm{O}\right)$ to generate an equilibrium $\mathrm{CO}+\mathrm{CO}_{2}$ pressure. The equilibrium pressure is proportional to the carbon activity, and, at $700^{\circ} \mathrm{C}$, is 743 Torr at a carbon activity of one.

The wustite layer required on the interior of the iron capsule was generated in place by filling the meter to about 250 Torr with a CO $(60 \%)$ and $\mathrm{CO}_{2}(40 \%)$ gas mixture and conditioning the meter at. $700^{\circ} \mathrm{C}$ in a $10 \mathrm{w}$-carbonactivity sodium system (a Type 304 stainless steel pot containing sodium). The pressure decreased parabolically to about 50 Torr over a three-day period as the $\mathrm{CO} / \mathrm{CO}_{2}$ reacted to form wustite and the carbon diffused out of the capsule into the sodium. The residual gas was pumped off and the meter was then ready for use. (It should be noted that the solubility of oxygen in iron is very low; the generated wustite layer remains within the capsule.) Since the meter relies on a pressure measurement, care was exercised in its construction to insure adequate leak tightness (the measured leak rate was less than $10^{-9} \mathrm{cc}$ (std) of $\mathrm{He} / \mathrm{sec}$ ). Sufficient annealing at high temperature $\left(700^{\circ} \mathrm{C}\right)$ and under vacuum was employed to eliminate any significant pressure drift due to outgassing. 
A variety of tab materials were suspended in the sodium from 11 hooks attached to the lowest baffle in the experimental assemblies (see Fig. 1). The tab materials tested and their initial carbon concentrations are listed in Table $\mathrm{I}$; the composition of the alloy tabs is given in greater detail in Table II. In a typical experiment, the tabs and the meter remained in the stirred sodium, held at a temperature of $700 \pm 2^{\circ} \mathrm{C}$, for a period of one week. The tabs were then withdrawn at temperature, cooled to room temperature in the box, cleaned with alcohol and water, and analyzed for their carbon content by combustion analysis using a LECO Carbon-Oxygen Determinator (Laboratory Equipment Corporation, St. Joseph, Michigan). This instrument is calibrated with a reference steel [Type 335 steel $(0.1 \%$ C) procured from the National Bureau of Standards] which is analyzed in the same way as the samples, The calibration curve is linear, and the background is equivalent to about $10 \mu \mathrm{g}$ of carbon. In a typical analysis, about $0.5 \mathrm{~g}$ of tab, accurately weighed (to $0.1 \mathrm{mg}$ ) is burned with $0.7 \mathrm{~g}$ of LECO Tin Metal Accelerator (Cat. No. 25075, Laboratory Equipment Corporation, St. Joseph, Michigan).

Experiments similar to those outlined above were also conducted in the following systems:

(1) A $1000-\mathrm{cm}^{3}$ alumina crucible containing about $800 \mathrm{~g}$ of sodium and held in an assembly consisting of a Type 200 nickel pot, baffles, and a stirrer. The sodium was saturated with carbon by addition and decomposition of excess disodium acetylide, equivalent to $300 \mathrm{ppm} \mathrm{C}$.

TABLE I. Characteristics of Experimental Tab Materials

\begin{tabular}{|c|c|c|c|}
\hline 'l'ab Material & $\begin{array}{l}\text { Initial Carbon } \\
\text { Content (ppm C) }\end{array}$ & $\begin{array}{c}\text { Tab Thickness } \\
\text { (mils) }\end{array}$ & Source ${ }^{a}$ \\
\hline $\begin{array}{l}\text { Fe-12 wt \% Mn } \\
\text { Fe-8 wt \% Ni } \\
\text { Type } 304 \text { Stainless Steel } \\
\text { Type } 321 \text { Stainless Steel } \\
\text { Ni } \\
\text { Fe } \\
\text { Co } \\
\text { Ti } \\
\text { V } \\
\text { Mo } \\
\text { Ta } \\
\text { Zr }\end{array}$ & $\begin{array}{r}38 \\
15 \\
340 \\
645 \\
19 \\
10 \\
10 \\
30 \\
163 \\
116 \\
50 \\
<5 \\
115\end{array}$ & $\begin{array}{l}2 \text { and } 5 \\
2 \text { and } 5 \\
3 \\
3 \\
5 \\
5 \\
5 \\
5 \\
5 \\
1 \\
5 \\
10\end{array}$ & $\begin{array}{l}1 \\
1 \\
2 \\
2 \\
1 \\
1 \\
1 \\
1 \\
1 \\
3 \\
3 \\
3\end{array}$ \\
\hline \multicolumn{4}{|c|}{$\begin{aligned} \mathrm{a}_{1}= & \text { Marz-grade metals and alloys from Materials Research } \\
& \text { Corporation, Orangeburg, N. Y. The Marz designation indicates } \\
& \text { a purity }>99.9 \% . \\
2= & \text { Standard carbon-equilibration alloys supplied by Westinghouse } \\
& \text { Electric Corporation, Advaneed Reactors Division, Madison, } \mathrm{Pa.} \\
3= & \text { High-purity }(>99.9 \%) \text { metals stocked at Argonne National } \\
& \text { Laboratory, Argonne, Illinois. }\end{aligned}$} \\
\hline
\end{tabular}


TABLE II. Composition of Alloys

\begin{tabular}{|c|c|c|c|c|}
\hline Element & $\mathrm{Fe}-12$ wt $\% \mathrm{Mn}$ & $\mathrm{Fe}-8$ wt $\% \mathrm{Ni}$ & Type 304 Ss & Type 321 SS \\
\hline \multicolumn{5}{|c|}{ (wt \% by atomic absorbtion analysis) ${ }^{a}$} \\
\hline Mn & 11.5 & & 1.44 & 1.55 \\
\hline $\mathrm{Ni}$ & & 7.5 & 9.38 & 9.12 \\
\hline $\mathrm{Cr}$ & & & 17.9 & 16.7 \\
\hline $\mathrm{T} i$ & & & & 0.48 \\
\hline \multicolumn{5}{|c|}{ (ppm by mass spectrographic analysis) $^{b}$} \\
\hline Mn & & 20 & & \\
\hline $\mathrm{Ni}$ & 1500 & & & \\
\hline $\mathrm{Cr}$ & 100 & 100 & & \\
\hline $\mathrm{Ti}$ & 3 & 5 & 20 & \\
\hline $\mathrm{P}$ & 30 & 70 & 300 & 150 \\
\hline S & 200 & 60 & 200 & 200 \\
\hline $\mathrm{Cl}$ & 2 & 3 & 2 & 2 \\
\hline $\mathrm{Ca}$ & 0.7 & 2 & 2 & 3 \\
\hline $\mathrm{V}$ & 3 & 3 & 1000 & 2000 \\
\hline Co & 30 & 50 & 2000 & 2000 \\
\hline $\mathrm{Cu}$ & 15 & 50 & 1500 & 1500 \\
\hline $\mathrm{Zn}$ & n.d. & n.d. & 30 & 30 \\
\hline $\mathrm{Ga}$ & n.d. & n.d. & 20 & 20 \\
\hline $\mathrm{Ge}$ & n.d: & n.d. & 10 & 10 \\
\hline As & 2 & 2 & 150 & 70 \\
\hline $\mathrm{Nb}$ & n.d. & n.d. & $: 7$ & 30 \\
\hline Mo & 7 & 3 & 1000 & 5000 \\
\hline $\mathrm{Sn}$ & n.d. & 2 & 50 & 50 \\
\hline $\mathrm{Sb}$ & n.d. & n.d. & 10 & 10 \\
\hline $\mathrm{Ta}$ & 30 & 30 & $\mathrm{n} . \mathrm{d}$. & 10 \\
\hline $\mathrm{W}$ & 100 & 50 & 10 & 300 . \\
\hline
\end{tabular}

(2) A section at $700^{\circ} \mathrm{C}$ of each of the following nonisothermal sodium loops at ANL (Illinois.):

(a) Oxygen Meter Rig (OMR)

(b) Test and Evaluation Apparatus (TEA)

(c) Apparatus for Monitoring and Purifying Sodium (AMPS)

(3) A section at $700^{\circ} \mathrm{C}$ of the Radioactive Sodium Chemistry Loop. (RSCL) on the primary system of the experimental breeder reactor, EBR-II, at ANL (Idaho).

The results of the experiments are given in Table III. The data accumulated in each of the experiments consist of (1) measured carbon concentrations. for the simultaneously exposed tab materials, and (2) the reading of the carbon meter that was in the system. (The meters, with the exception of the pressure meter, generally reached a steady-state reading within one to two days. The pressure meter required three to six days to reach equilibrium.) 
TABLE III. Carbon Concentration in Tab Materials and Carbon Meter Readings in $700^{\circ} \mathrm{C}$ Sodium

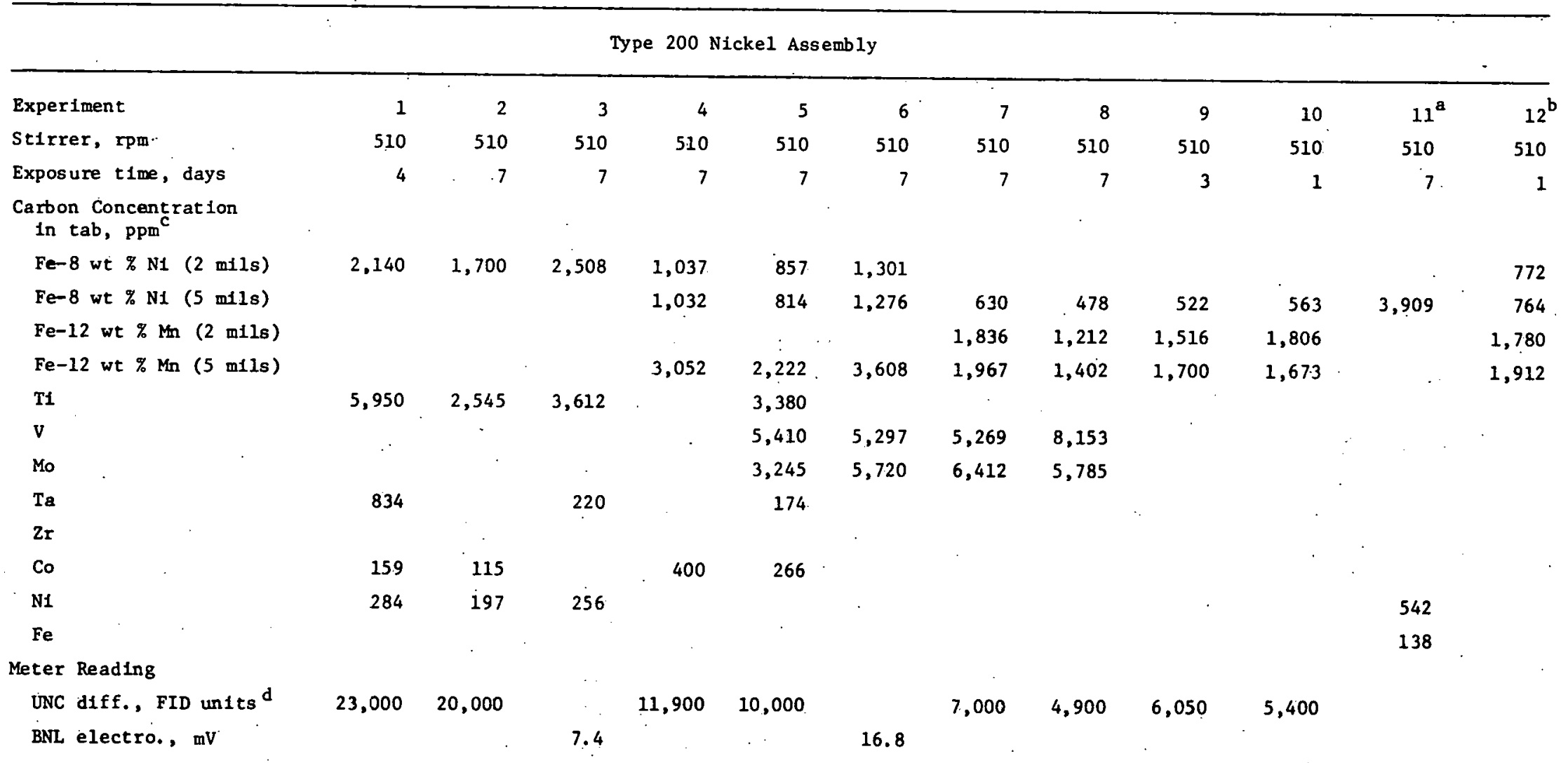


TABLE III. (Cont'd)

Type 200 N1ckel Assembly

\begin{tabular}{|c|c|c|c|c|c|c|c|c|c|c|c|c|}
\hline Experiment & 13 & 14 & 15 & 16 & 17 & 18 & 19 & 20 & $21^{e}$ & $22^{e}$ & $23^{e}$ & $24^{e}$ \\
\hline Stịrrer, rpm & 510 & 510 & 0 & 510 & 510 & 510 & 970 & 785 & 510 & 785 & 785 & 510. \\
\hline Exposure time, days & 7 & 7 & 7 & 7 & 7 & 3 & 7 & 7 & 7 & 7 & 7 & 7 \\
\hline $\begin{array}{l}\text { Carbon Concentration } \\
\text { in tab, } \mathrm{ppm}^{\mathrm{c}}\end{array}$ & & & & & & & & & & & & \\
\hline $\mathrm{Fe}-8$ wt $\% \mathrm{Ni}(5 \mathrm{mlls})$ & 204 & 171 & $\because$ & & & & 185 & 109 & 1,167 & 284 & 575 & \\
\hline $\mathrm{Fe}-12$ wt $\% \mathrm{Mn}(5 \mathrm{~m} 1 \mathrm{~s})$ & 678 & 582 & 439 & 41.9 & 181 & 573 & 600 & 328 & 3,725 & 812 & & 2,210 \\
\hline Type 304 ss & 9,795 & 6,950 & 2,688 & $3,7 \in I$ & 1,179 & 3,986 & 10,621 & & & & & \\
\hline Type $321 \mathrm{ss}$ & 10,800 & 9,330 & 4,231 & 6,110 & 2,570 & 5,291 & 11,190 & & & & & \\
\hline Meter Reading & & & & & & & & & & & & \\
\hline UNC diff., FID units ${ }^{d}$ & 1,450 & 1,230 & 500 & 720 & & $1 ; 090$ & 1,650 & & 12,300 & & & \\
\hline H1gh-area diff., FID units ${ }^{d}$ & & & & & & & & 3,115 & & 4,650 & & \\
\hline $\begin{array}{l}\text { ANL electro., mV } \\
\text { ANL pressure, Torr }\end{array}$ & & & & & & & & & & & 211 & 125.7 \\
\hline
\end{tabular}


TABLE III.. (Cont' ${ }^{\prime}$ d $)$

Type 304 Stainless Steel Assembily

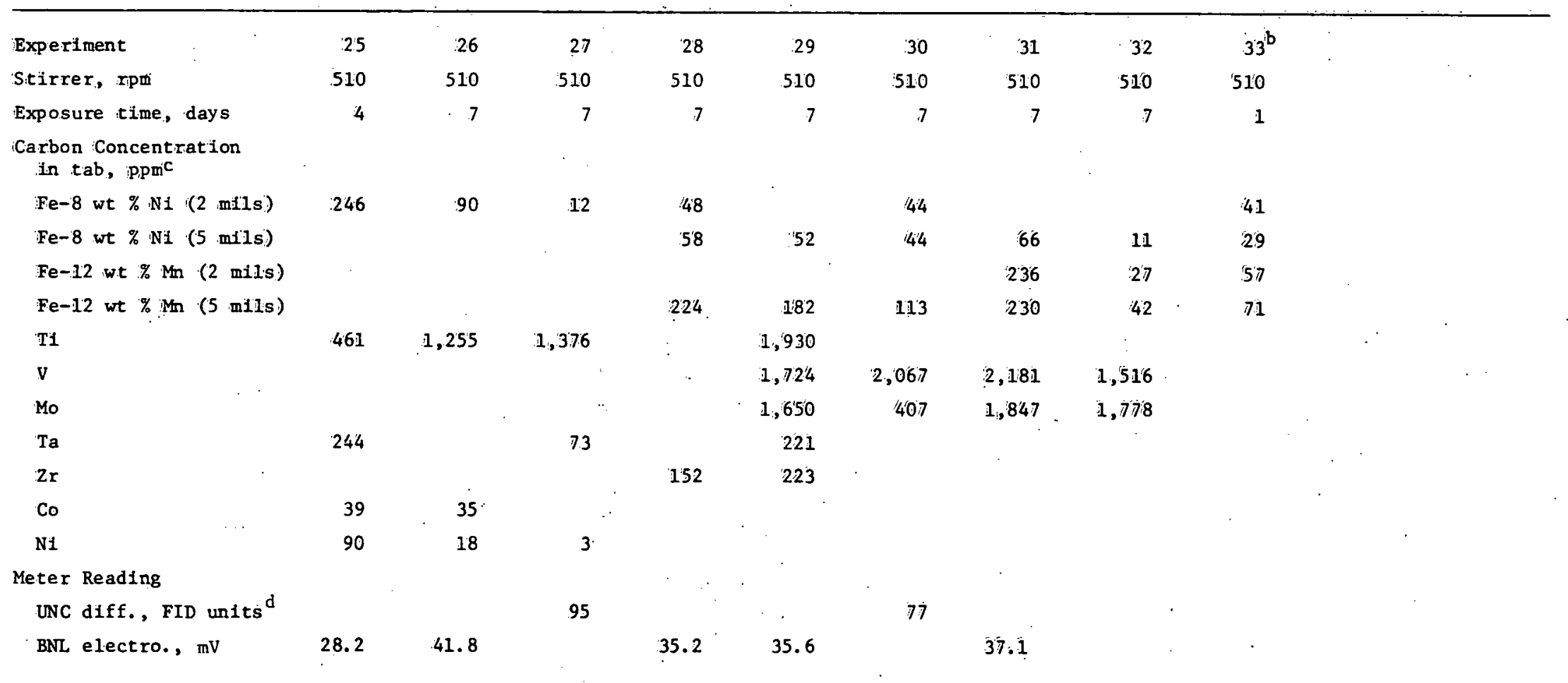


TABLE III. (Cont'd)

Type 304 Stainless Steel Assembly

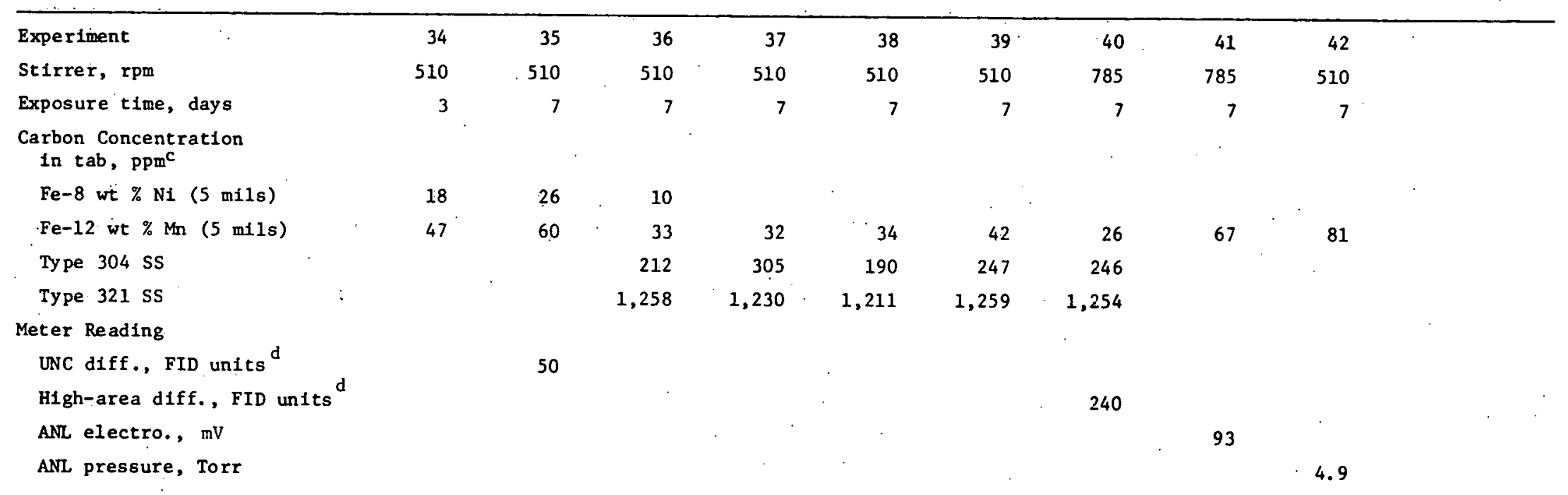


TABLE TII. (Cont"d)

Noni-sothermal Sodium Systems

\begin{tabular}{|c|c|c|c|c|c|c|c|c|c|}
\hline System & TEA & OMR & OMR & OMR & 'OMR & 'OMR & AMPS & EBR-II & \\
\hline Exposure ttime,.. day.s & 3 & 3 & 3 & 3 & 0.3 & 30 & 3 & 3 & $\cdot$ \\
\hline $\begin{array}{l}\text { Carbon Concentration } \\
\text { in tab, } \mathrm{ppm}^{\mathrm{C}}\end{array}$ & & & v & & & & & & \\
\hline Fe- 8 w.t $\%$ Ni ( $(5$ mils $)$ & 44 & 10 & & & & & & 11 & \\
\hline Fe-il2 wit \% Mn ('5 imilis) & 123 & 34 & 38 & 477 & & & 40 & 30 & \\
\hline Type 304 S'S & & & 30 & 33 & & & 41 & 23 & . \\
\hline Type 321 SS & & & & 9.55 & & & . & . & . \\
\hline Meter Reading & & & & & & & & & \\
\hline High-area diffi. , FID units ${ }^{\text {i, if }}$ & & & & & 140 & & & & \\
\hline ANL pressure, 'Torr & & & & & & 2.2 to 0.75 & $\because$ & & \\
\hline
\end{tabular}

The sodium was contained in a $1000-\mathrm{cm}^{3}$ alumina cirucible within the Type 200 nilckel a'ssembly, and was isaturated with carbon by decomposittion of excess disodium acétylide, equivalent to about 300 ppm $C$.

$\mathrm{b}_{7 \prime} 50^{\circ} \mathrm{C}$ : experiments.

${ }^{C}$ The values quoted are average carbon concentrations deteruined usually from two or three analyses. Duplícáte analysés normally di'sagreed by no more than $3 \%$ at a level of $11000 \mathrm{ppm}$ and $15 \%$ at a level of 50 ppin.

' $d_{\text {The }}$ Flame Ionization Detector (FID) used with diffusion meters has an arbitirary current readout itermed (FID) anits. This reading may be converted, if desired, to a carbon flux by calibrating the méter with ga's's containing knisin. concentrations of methane.

New nickel assembly. used in these runs.

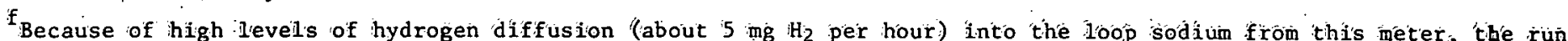
was terminated after seven hours. The FID reading was stable at 140 Fid unit's for the last three hours. The carbon activity in the sodium during this run was estimated from Fe-8 wt $\% \mathrm{Ni}$ and $\mathrm{Fe}-12$ wt $\%$ Mn data obtalned in the other OMR runs. 
The earliest experiments (1-12 and 25-33 in Table III) in both the Type 200 nickel and Type 304 stainless steel assemblies dealt primarily with simpler tab materials and with carbon meters that had been developed in previous studies. Later work dealt with more complicated alloys, such as Type 304 stainless steel, and carbon meters designed during the course of this work.

The wide range of carbon concentrations observed in some of the tab materials (see Table III) is indicative of the wide range of carbon activities provided in these experiments. This range was at ained through the use of different materials of construction for the pot, baffle, and stirrer assemblies. The Type 304 stainless steel assembly decarburized the sodium to a low carbon activity (about $5 \times 10^{-3}$ ) by forming stable, chromium-rich carbides in the steel; many of the tabs exposed to the sodium in this assembly had relatively low carbon concentrations. The Type 200 nickel assembly, because of its high carbon concentration and the instability of nickel carbides, carburized the sodium to a h1gh carbon activity. (about 0.5), and, therefore, tabs exposed in this assembly had relatively high carbon concentrations. Repeated experimentation in the nickel assembly slowly decarburized it from its initially high carbon activity to about the same level of carbon activity as that encountered in the Type 304 assembly. The wide activity range thus provided was essential for testing and evaluating the tabs and meters. 
III. DISCUSSION

A. Tab Materials: $\mathrm{Fe}-12$ wt $\% \mathrm{Mn}$ and $\mathrm{Fe}-8$ wt $\% \mathrm{Ni}$

Experiments with $\mathrm{Fe}-12$ wt \% $\mathrm{Mn}$ and $\mathrm{Fe}-8$ wt \% $\mathrm{Ni}$ tabs were conducted to determine the times required for equilibration and the curves of carbon activity vs. carbon concentration. The equilibration times may have depended on a combination of limiting factors in the sodium, at the sodium/tab interface, and within the tab itself. Therefore, it was necessary to demonstrate that equilibrium had been achieved. Equilibration times could not be directly determined by comparing the carbon concentration in tabs exposed for shorter and longer times, because the carbon activity in the experimental assemblies varied from experiment to experiment. Consequently, indirect methods were employed.

The use of both 2-mil- and 5-mil-thick tabs of $\mathrm{Fe}-8$ wt $\% \mathrm{Ni}$ and $\mathrm{Fe}-12$ wt \% Mn provided one means of determining whether equilibrium with respect to carbon was achieved for these alloys. For instance, the agreement between carbon concentrations for the two thicknesses of $\mathrm{Fe}-8$ wt \% Ni (Expts. 4 through 6 in Table III) established that the 5-mil-thick tabs of this alloy were in equilibrium after a seven-day exposure at $700^{\circ} \mathrm{C}$. The interpretation of similar equilibration tests on $\mathrm{Fe}-12$ wt \% Mn (Expts. 7 through 10 in Table III) was somewhat more complicated because, except for the one-day run, the carbon concentration in the thicker tabs exceeded that in the thinner tabs by about 10 percent. This anomalous result occurred because of a diffusonal loss of manganese, the element responsible for high carbon concentration in the Fe-Mn alloy. The lower carbon concentration in the thinner tabs in the three-day and seven-day runs was caused by a loss of approximately one-tenth of their manganese; the thicker tabs lost only one-twentieth of their manganese. (Manganese losses were determined by atomic-absorption analyses of the starting materials and of the tabs exposed in these runs.) The small loss, (about one-twentieth of the manganese) was found to occur consistently in both the pot and the loop runs for the thicker Fe-12 wt \% $\mathrm{Mn}$. Because of this consistency, the small loss presented no serious problems in practical application of the Fe-12 wt \% Mn tab method. The ratio of the thin-tab carbon concentrations to thick-tab carbon concentrations for $\mathrm{Fe}-12$ wt \% Mn in the three-day run, 0.89 , is nearly the same as the average of this ratio for the seven-day runs, 0.90. The lack of change in the ratio demonstrates that, at $700^{\circ} \mathrm{C}$, a three-day exposure of the 5-mil tabs of $\mathrm{Fe}-12$ wt \% $\mathrm{Mn}$ is sufficient for carbon equilibration.

In the study of sodium systems, it would be advantageous to measure both oxygen and carbon at the same time. Since the vanadium-wire equilibration method for oxygen is carried out at $750^{\circ} \mathrm{C},{ }^{3}$ two tests for carbon were carried out at this temperature (Expts. 12 and 33 in Table III). In these 24-hour tests, 2-mil and 5-mil tabs of $\mathrm{Fe}-8$ wt $\% \mathrm{Ni}$ and $\mathrm{Fe}-12$ wt \% $\mathrm{Mn}$ were used. The equality of carbon concentration in the 2-mil and 5-mil Fe-8 wt \% $\mathrm{Ni}$ tabs demonstrated that 5 -mil tabs of $\mathrm{Fe}-8$ wt $\% \mathrm{Ni}$ were equilibrated in one day at $750^{\circ} \mathrm{C}$. As in the $700^{\circ} \mathrm{C}$ runs, manganese losses from the 2-mil and 5-mil $\mathrm{Fe}-12$ wt \% Mn tabs were found to be about one-tenth and one-twentieth of the total, respectively, and the carbon concentration was again lower in the thinner tabs than in the thicker tabs. (The carbon concentration in the 2-mil tabs was about $93 \%$ of that in the 5 -mil tabs.) This similarity to the $700^{\circ} \mathrm{C}$ 
experiments does not establish that the 5-mil Fe-12 wt \% Mn tabs were equilibrated in the $750^{\circ} \mathrm{C}$ runs. It will be shown later that carbon activities calculated from the 5-mil $\mathrm{Fe}-8$ wt \% $\mathrm{Ni}$ tab data were in good agreement with carbon activities calculated from the 5-mil Fe-12 wt \% Mn tab data for these $750^{\circ} \mathrm{C}$ runs. This agreement directly established that the 5-mil Fe-12 wt \% Mn tabs were equilibrated, because the 5-mil $\mathrm{Fe}-8$ wt $\% \mathrm{Ni}$ was shown to be at equilibrium with respect to carbon in these runs. (A discussion of the activity comparisons, which employ equations from gas-equilibration studies, is presented below after first establishing that sodium equilibration and gas equilibrations give essentially identical curves of carbon concentration $v s$. carbon activity for these $\mathrm{Fe}-\mathrm{Ni}$ and Fe-Mn alloys.)

Carbon activity $v s$. carbon concentration curves are commonly established for metals and their alloys through equilibrations in either $\mathrm{CO} / \mathrm{CO}_{2}$ or $\mathrm{CH}_{4} / \mathrm{H}_{2}$ gas mixtures.1,9-12 A metal such as iron or nickel, for which the relationship of carbon concentration to carbon activity is known quite accurately, is usually included for the purpose of calibrating the carbon activity of the gas mixture. In addition, gas equilibrations occasionally are done in the presence of excess graphite to establish a system in which $a_{c}=1$, for the purpose of measuring carbon solubilities. Extension of these techniques to the sodium experiments provided a simple means for determining curves of carbon activity $v s$. carbon concentration. The curves thus established in. sodium are expected to agree with curves determined by gas equilibrations for the $\mathrm{Fe}-\mathrm{Ni}$ alloy ${ }^{1}, 10$ and Fe-Mn alloy. ${ }^{1}$ Agreement serves to confirm the validity of the tab-equilibration method in sodium.

The curve of carbon activity vs. concentration for $\mathrm{Fe}-8 \mathrm{wt} \% \mathrm{Ni}$ was determined in part by measuring the solubility of carbon in Fe-8 wt \% Ni at. $700^{\circ} \mathrm{C}$. This measurement. (Expt. 11, Table III) consisted of an equilibration in sodium containing excess disodium aretylide $\left(\mathrm{Na}_{2} \mathrm{C}_{2}\right)$, and included tabs of $\mathrm{Fe}, \mathrm{Ni}$, and $\mathrm{Fe}-8 \mathrm{wt} \% \mathrm{Ni}$. The excess acetylide was found to decompose at high temperature to yield graphite as a separate phase. (After the equilibration, a continuous sheet of graphitized carbon was found on the tabs. A portion of the sheet, which was easily removed intact from the $\mathrm{Fe}-8 \mathrm{wt} \% \mathrm{Ni}$ tabs, was burned, leaving no visible residue; the remainder was submitted for examination by $X$-ray diffraction. The only diffraction line observed in the spectrum was the strong $\mathrm{d}_{002}$ line of graphite.) Because of the presence of layers of carbon on the surface of the tabs, they were electropolished prior to carbon analysis. The carbon concentrations in the electropolished nickel and iron tabs were $542 \pm 40$ and $138 \pm 8 \mathrm{ppm} \mathrm{C}$, respectively. These values are in good agreement with recommended values for the solubility of graphite in nickel and iron, namely, $520 \mathrm{ppm} \mathrm{C}^{10}$ and $127 \mathrm{ppm} \mathrm{C}{ }^{9}$, respectively. The solubility of carbon in $\mathrm{Fe}-8 \mathrm{wt} \% \mathrm{Ni}$ at $700^{\circ} \mathrm{C}$ was taken to be the average of the measured carbon concentrations from this experiment, $3909 \pm 70 \mathrm{ppm} \mathrm{C}$.

Bodsworth and coworkers ${ }^{12}$ showed that carbon activity is proportional to $\mathrm{N}_{c} /\left(1-5 \mathrm{~N}_{\mathrm{c}}\right)$, where $\mathrm{N}_{\mathrm{c}}$ is the carbon mole fraction in the tab material for a wide range of austenitic alloys, including Fe-Ni and Fe-Mn alloys. By converting $\mathrm{N}_{c}$ in $\mathrm{N}_{c} /\left(1-5 \mathrm{~N}_{c}\right)$ to $\mathrm{ppm} \mathrm{C}$ and adjusting this term to give a carbon solubility of $3909 \mathrm{ppm}^{\mathrm{C}} \mathrm{C}$, the relationship between carbon activity and carbon concentration is, therefore, given by:

$$
a_{c}=\frac{p p m C}{4234-0.083(p p m C)} \quad\left(\text { for } \mathrm{Fe}-8 \text { wt } \% \mathrm{Ni} \text { in } 700^{\circ} \mathrm{C} \mathrm{Na}\right. \text { ) }
$$


Tabs of both $\mathrm{Fe}-8$.wt $\% \mathrm{Ni}$ and ' $\mathrm{Ni}$ :were also equilibrated in experiments 1 , $2,3,28,29$, and 30 (Tabile IIII). Caŕbon concentrations in these tabs were converted to carbon activity, using the above relationship for $\mathrm{Fe}-8$ w $\% \mathrm{~N} \cdot \mathrm{i}$ tabs and the ratio of the imeasured carbon concentration to the rcarbon solubility for $\mathrm{Ni}$ tabs. A comparison of the carbon activities as determined by $\mathrm{Fe}-8$ wt \% $\mathrm{Ni}$ and by ' $\mathrm{Ni}$ is given in Table IIV, twere the agreement is seen to be fairly good. Since $\mathrm{Fe}-8$, wt $\%$ i $\mathrm{Ni}$ contains about eight times as much carbon as does $\mathrm{Ni}$ at a given activity, the ' $\mathrm{Fe}-8 \mathrm{iwt} \% \mathrm{Ni}$ iresults are presumed to be more accurate than the $\mathrm{Ni}$ results.

The relationship between carbon activity and carbon concentration for 5-mil thick tabs of $\mathrm{Fe}=12$ wt \% Mn at a temperature of $700^{\circ} \mathrm{C}$ 'was determined from those experiments in Table III that included both $\mathrm{Fe}-8$ wt \% Ni and $\mathrm{Fe}-12$ wt $\% \mathrm{Mn}$ tabs. The data, plotted in Fig. 16, were used to calculate the following equation for the activity of carbon in $\mathrm{Fe}-12$ wt \% $\mathrm{Mn}$ :

$$
a_{c}=\frac{p p m c}{13480-0.264(p p m ~ C)} \quad\left(\text { for } \mathrm{Fe}-12 \text { wt } \% \text { Mn in } 700^{\circ} \mathrm{C} \mathrm{Na}\right)
$$

TABLE IV. Carbon Activity in $700^{\circ} \mathrm{C}$. Sodium as Determined by $\mathrm{Fe}-8$ wit \% $\mathrm{Ni}$ and by $\mathrm{Ni}$ Tábs

\begin{tabular}{ccc}
\hline \multirow{2}{*}{$\begin{array}{c}\text { Experiment } \\
\text { from Table III }\end{array}$} & \multicolumn{2}{c}{ Carbon Activity } \\
\hline 1 & 0.53 & Nickel \\
2 & 0.42 & 0.55 \\
3 & 0.62 & 0.38 \\
28 & 0.06 & 0.49 \\
29 & 0.02 & 0.17 \\
30 & 0.003 & 0.03 \\
& & 0.006 \\
\hline
\end{tabular}

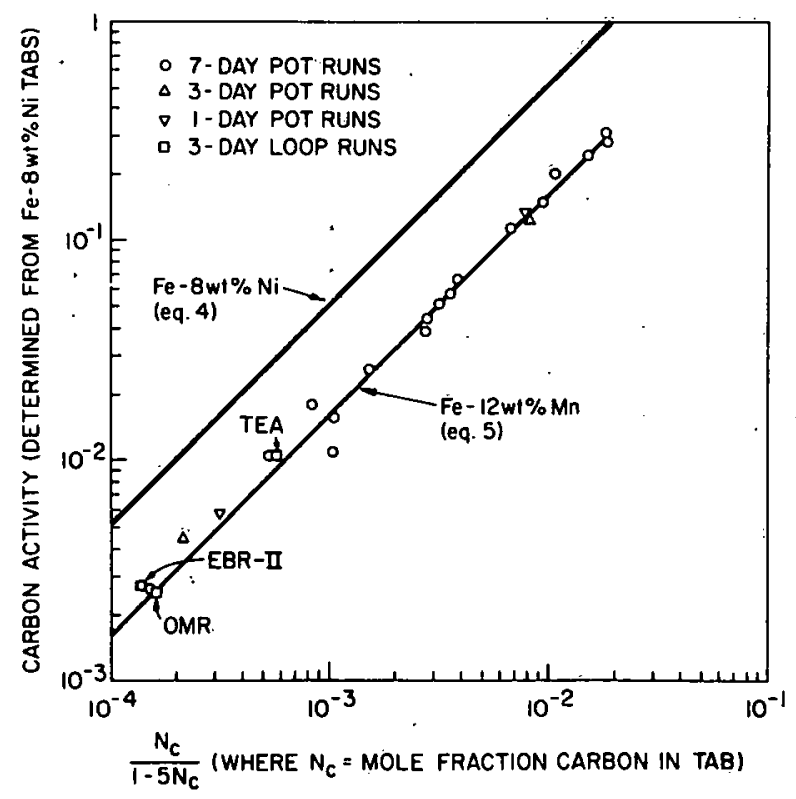

Fig. 6.

Carbon Concentration in $\mathrm{Fe}-12$ wt \% Mn Tabs, Expressed as $\mathrm{N}_{\mathrm{c}} /\left(1-5 \mathrm{~N}_{\mathrm{c}}\right)$, as a Function of Carbon Activity. (Activity measured with $\mathrm{Fe}-8$ wt $\% \mathrm{Ni}$ tabs in $700^{\circ} \mathrm{C}$ sodium.) 
An inspection of the curves for $\mathrm{Fe}-12$ wt $\% \mathrm{Mn}$ and $\mathrm{Fe}-8$ wt $\% \mathrm{Ni}$ in $\mathrm{Fig} .6$ shows that, at a given activity, the Fe-12 wt \% Mn contains about three times as much carbon as does Fe-8 wt \% Ni. This higher sensitivity, which makes possible more accurate measurement of low carbon activities in loops and reactors, led to the choice of $\mathrm{Fe}-12 \mathrm{wt} \% \mathrm{Mn}$ for use in the tab-equilibration method. ${ }^{4}$ Equations 4 and 5 agree, within about 5\%, with the gas-equilibration results of Natesan et al. ${ }^{1}$ (for $\mathrm{Fe}-8 \mathrm{wt} \% \mathrm{Ni}$ ) and of Tsuguyasu Wada et al. ${ }^{1}$ (for $\mathrm{Fe}-12$ wt \% $\mathrm{Mn}$ ), thus confirming the validity of the tab-equilibration method in sodium.

For carbon concentrations above $0.5 \mathrm{wt} \% \mathrm{C}$ in $\mathrm{Fe}-12$ wt $\% \mathrm{Mn}$ at $700^{\circ} \mathrm{C}$, a carbide precipitate forms in the alloy, 13 and the expression relating carbon concentration to carbon activity in the alloy then differs from Eq. 5. To monitor carbon activities above 0.4 (an activity which gives $0.5 \mathrm{wt} \% \mathrm{C}$ in $\mathrm{Fe}-12$ wt \% $\mathrm{Mn}$ ), tabs of $\mathrm{Fe}-8$ wt \% $\mathrm{Ni}$ may be used in conjunction with $\mathrm{Eq} .4$, an equation that is valid for carbon activities as high as 1.0 .

Carbon activity measurements with $\mathrm{Fe}-8$ wt $\% \mathrm{Ni}$ and $\mathrm{Fe}-12$ wt \% $\mathrm{Mn}$ in TEA, $O M R$, and EBR-II are included in Fig. 6. (The carbon activity at $700^{\circ} \mathrm{C}$ in EBR-II sodium was found to be $2.2 \times 10^{-3}$.) These data indicate that stainless steel-sodium systems normally operate at a very low carbon activity, typically $10^{-2}$ to $10^{-3}$. Stainless steel-tab equilibrations and measurements with carbon meters in these systems are discussed in later sections of this report.

The data from three-day and one-day runs, included in Fig. 6, fall along the same curve as the seven-day runs. Therefore, if an equilibration period of less than seven days is adequate for one of the tab materials, it is adequate for both. Three days at $700^{\circ} \mathrm{C}$ was shown above to be sufficient for equilibration of the 5-mil-thick Fe-12 wt \% Mn tabs at $700^{\circ} \mathrm{C}$ frum a comparison of carbon concentrations in 2-mil tabs and 5-mil tabs. Therefore, a three-day exposure at $700^{\circ} \mathrm{C}$ is also sufficient for the equilibration of $5-\mathrm{mil}$ tabs of $\mathrm{Fe}-8$ wt \% $\mathrm{Ni}$. The earlier comparison of 2 -mil and 5-mil $\mathrm{Fe}-12$ wt \% Mn data showed, in addition, that a one-day exposure at $700^{\circ} \mathrm{C}$ was insufficient for equilibration of 5-mil tabs of this alloy. Therefore, a one-day exposure at $700^{\circ} \mathrm{C}$ is also insufficient for equilibration of 5 -mil tabs of $\mathrm{Fe}-8$ wt \% Ni:

In the case of the $750^{\circ} \mathrm{C}$ runs, carbon activities in the 5-mil-thick tabs were calculated from the equations of Wada and coworkers. 10,11 The calculated carbon activities, listed in Table V, are seen to be in good agreement.

TABLE V. Carbon Activity in $750^{\circ} \mathrm{C}$ Sodium as Determined by $\mathrm{Fe}-8$ wt \% $\mathrm{Ni}$ and $\mathrm{Fe}-12$ wt \% Mn Tabs

\begin{tabular}{lcc}
\hline \multicolumn{2}{c}{$\begin{array}{c}\text { Experiment } \\
\text { from Table III }\end{array}$} & \multicolumn{2}{c}{ Carbon Activity } \\
\hline 12 & $\mathrm{Fe}-8 \mathrm{wt} \% \mathrm{Ni}$ & $\mathrm{Fe}-12 \mathrm{wt} \% \mathrm{Mn}$ \\
\hline 33 & $4.4 \times 10^{-3}$ & 0.115 \\
\hline
\end{tabular}


Since 5-mil $\mathrm{Fe}-8$ wt \% $\mathrm{Ni}$ tabs were shown above to be equilibrated in one day at $750^{\circ} \mathrm{C}$ by comparison of 2-mil and 5-mil tab data, this good agreement confirms that $\mathrm{Fe}-12$ wt $\% \mathrm{Mn}$ is equilibrated in one day at $750^{\circ} \mathrm{C}$.

\section{B. Tab Materials: Ta, $\mathrm{Zr}, \mathrm{Co}, \mathrm{Ti}, \mathrm{V}$, and Mo}

The early experiments with $\mathrm{Ta}, \mathrm{Zr}$, and $\mathrm{Co}$ showed that their carbon concentrations after exposure were generally low (see Table III). These metals were not included in later experiments because their low carbon concentrations made them poor monitors of carbon activity.

The seven-day experiments with Ti, $\mathrm{V}$, and Mu are plotted in Fig. 7 in a manner similar to that used in Fig. 6 for the Fe-12 wt \% Mn data. Even though the scatter in the data in Fig. 7 is relatively large, general trend lines have been indicated for $\mathrm{Ti}, \mathrm{V}$, and Mo. The amount of carbon picked up by titanium in a one-week run is seen to be nearly independent of carbon activity in the sodium. Titanium is, therefore, an effective carbon getter. The scatter in the $\mathrm{Ti}, \mathrm{V}$, and Mo data may be due, in part, to the interaction of these metals with other impurities, such as oxygen and hydrogen, that are present in the sodium. Because of the relative insensitivity of $\mathrm{Ti}, \mathrm{V}$, and Mo to changes in carbon activity and because of the scatter of the data in Fig. 7, Ti, V, and Mo were not considered to be useful carbon-activity monitors.

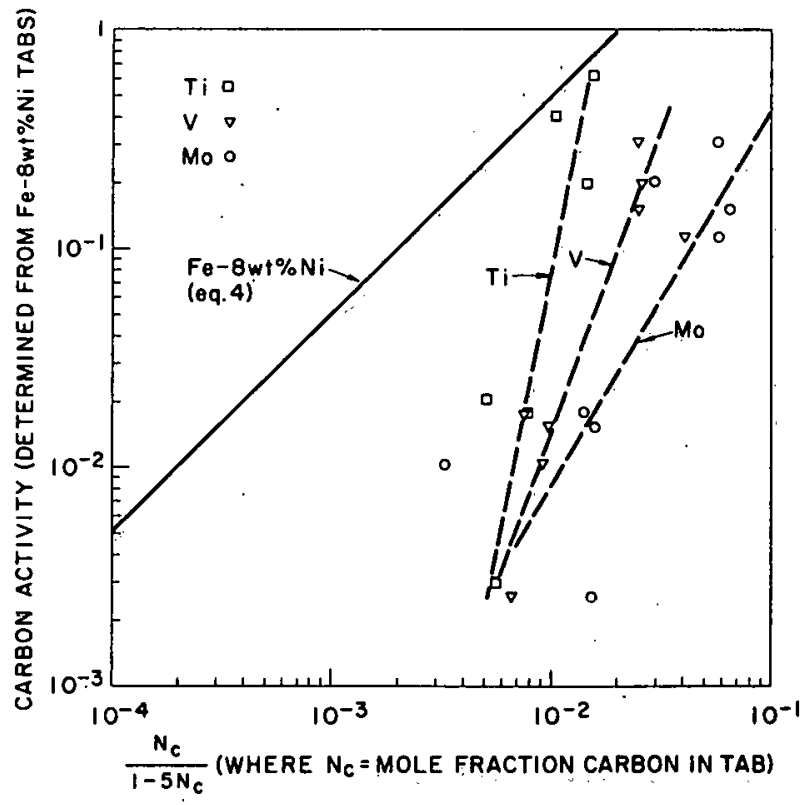

Fig. 7. Carbon Concentration in Ti, V, and Mo Tabs, Expressed as $\mathrm{N}_{\mathrm{C}} /\left(1-5 \mathrm{~N}_{\mathrm{C}}\right)$, as a Function of Carbon Activity. (Seven-day runs in $700^{\circ} \mathrm{C}$ sodium.) 


\section{Response of Diffusion-type Meters to Carbon in Sodium}

Two diffusion-type carbon meters were tested in the experiments. The operation of these meters is described in Section II and a diffusion:meter is illustrated in Fig. 2. As noted in the introduction, one of the major objectives of this study was to characterize the performance of carbon meters. The tab method, described in Section III-A., provided a simple and effective technique for carrying out the required performance studies.

The diffusion-type carbon meters and the Type 304 stainless steel tabs were found to exhibit parallel responses to carbon in sodium. The response of the diffusion-type carbon meters, because it is somewhat simpler to analyze than that of the stainless steel tabs, is treated first to demonstrate some of the important factors involved in carbon transport in a sodium system. The response of the stainless steel tabs.will then be discussed in the following section. The major finding in these analyses is that transport processes occurring in the sodium itself are rate-limiting to a surprising extent, and it cannot be assumed that in sodium-stainless steel systems carbon transport is limited only by the kinetics of carbon diffusion in the stainless steels.

The readings of the UNC meter and high-area meter are plotted in Fig. 8

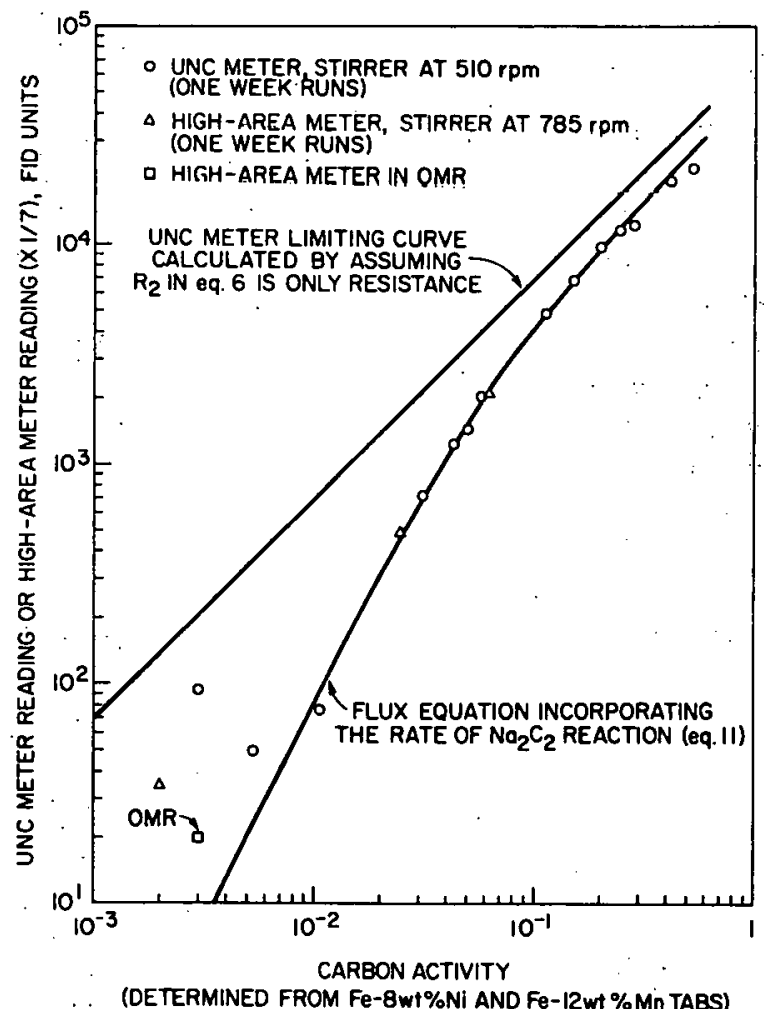

Fig. 8. Response of UNC and High-Area Diffusion-Type Carbon Meters to Carbon in Sodium at $700^{\circ} \mathrm{C}$ 
against carbon activity, as determined by carbon analysis of equilibrated $\mathrm{Fe}-8$ wt \% $\mathrm{Ni}$ and $\mathrm{Fe}-12$ wt \% $\mathrm{Mn}$ tabs. (These meter readings, given in $\mathrm{FID}$ units, are proportional to the concentration of $\mathrm{CO}$ in the decarburizing gas. The high-area-meter readings have been multiplied by a factor of one-seventh to normalize the differences in efficiency of the two meters that arise because of differences in construction.) The evident nonlinearity of these data led to an examination of the factors controlling the response of the meters. The flux of carbon through the iron membrane of the meters is controlled by the following:

(1) The rate of reaction of the moist hydrogen-argon gas with carbon at the gas-iron membrane interface.

(2) The rate of carbon diffusion through the iron membrane.

(3) The rate of reaction of carbon in the sodium with the iron membrane at the sodium-membrane interface.

(4) The rate of transport of carbon through the sodium to the iron membrane.

If each of these reactions could be represented by a rate proportional to the difference in carbon activity through each phase or interface, then the steady-state carbon flux, $F$, would be given by the equation

$$
F=\frac{{ }_{c}}{R_{1}+R_{2}+R_{3}+R_{4}}
$$

where $a_{c}$ is the chemical activity of carbon in the bulk of the sodium, and $R_{1}, R_{2}, R_{3}$, and $R_{4}$ are the resistances associated with each of the rates enumerated above. ( $R$ is the rcciprocal of the respective rate constant.) We have ignored here a minor correction for the very low carbon activity of the decarburizing gas mixture. This correction is very small in comparison with the term given on the right in Eq. 6 (see, for example, Ref. 6).

Thus, if the resistances were constant, the flux would vary linearly with the activity of carbon in the sodium. The observed nonlinearity in the meter-calibration curves in Fig. 8 could have been caused by a variation with activity of any one of the resistances (corresponding to a process that is not first-order with respect to activity) or to nonlinearity in either the flux or activity measurements. We have conducted experiments, described in the following paragraphs, that tend to eliminate $R_{1}, R_{2}, R_{4}$, the flux, and the activity measurements as possible causes of the nonlinearity; thus, $a$ variation in the resistance associated with the rate of reaction at the sodium-membrane interface, $\mathrm{R}_{3}$, appears to be the most likely possibility.

Hudson ${ }^{14}$ has shown that the diffusion-limited decarburization of iron by a gas mixture containing water and hydrogen is first-order with respect to carbon activity. This demonstrates directly that the sum of $R_{1}$ and $R_{2}$ in Eq. 6 . is independent of carbon activity. However, further simple tests of $R_{1}$ and $R_{2}$ were undertaken in this work. The combined influence of $R_{1}$ and $R_{4}$ was tested by reducing the effect of these two resistances on the UNC-meter carbon flux; this was accomplished by increasing the water content of the 
decarburizing gas and by increasing the stirring speed. An increase in the water content of the decarburizing gas from the normal content of $0.7 \%$ to $1.4 \%$ and an increase in the stirring speed from the normal level of $510 \mathrm{rpm}$ to $97.0 \mathrm{rpm}$ increased the UNC-meter reading by about $30 \%$ at carbon activities of $0.2,0.06$, and 0.01 ; the nonlinearity of the calibration curve was unaffected. Thus, $\left(R_{1}+R_{4}\right)$ is not a function of carbon activity. The $30 \%$ increase in meter reading brought the calibration curve in Fig. 8 quite close to the limiting curve* at the relatively high carbon activity of 0.2 . This finding suggests that the influence of $\left(R_{1}+R_{4}\right)$ on the rate has been made quite smal1. The nonlinearity is, therefore; not associated with $R_{1}$ or $R_{4}$ in Eq. 6.

$\mathrm{R}_{2}$ was tested indirectly by calibrating the high-area meter. This meter has a high-purity iron membrane that should have a constant resistance to carbon diffusion over a wider range of activities than does the commercial grade of iron used in the membrane of the UNC meter. Thus, if the nonlinearity were associated with the iron membrane in the UNC meter, a more nearly linear response would have been found in the tests with the high-area meter. Since the high-area meter and UNC meter exhibit nearly the same dependence on carbon activity, $R_{2}$ was ruled out as the cause of the nonlinearity.

The flux measurements and the activity measurements were also excluded as causes of nonlinearity. The response of the flux-measurement system is known to be linear from routine analyses of $\mathrm{CO}$ and $\mathrm{CH}_{4}$ calibration gases whose concentrations extended throughout the region of interest. Moreover, the accuracy of the activity measurements had been established above by the following: (1) the excellent agreement of $\mathrm{Fe}-8$ wt $\% \mathrm{Ni}$ and $\mathrm{Fe}-12 \mathrm{wt} \% \mathrm{Mn}$ tab-equilibration data over the activity range from 0.002 to 0.3 , and (2) demonstration of the agreement between measurements of carbon concentrations vs. carbon activity for $\overrightarrow{\mathrm{Fe}}-8$ wt $\% \mathrm{Ni}$ and $\mathrm{Fe}-12 \mathrm{wL} \% \mathrm{Mn}$ in sodium and eimilar measurements by gas-equilibration methods.1,10,11

Thus, by a process of elimination, the resistance associated with the rate of reaction of carbon at the sodium-membrane interface ( $R_{3}$ in $\left.E q .6\right)$ was taken to be the probable cause of the nonlinearity. Some investigators have succeeded in fitting nonlinear fluxes by incorporating a Langmuir adsorption isotherm into the rate equation (see, for example, the discussion of hydrogen diffusion in metals given by Dushman ${ }^{15}$ ). This approach was not used here because Darken and Turkdogan ${ }^{16}$ have shown that surface adsorption phenomena lead to a limitation in iron decarburization rates at high, rather than low, carbon activities, the rate at low activities being proportional to $a_{c}$. The meter response shown in Fig. 8 is approximately proportional to $a_{c}^{2}$ at low activities and to $a_{c}$ at high activities; this suggests a simple choice for the interface reaction. If disodium acetylide (or the acetylide ion) is the dominant form of carbon dissolved in sodium, and if its reaction with the iron membrane is relatively slow, the desired variation of the flux with $a_{c}^{2}$ will be observed at low activities. On the basis of their studies

\footnotetext{
The limiting curve is calculated by assuming that diffusion through the iron membrane is the only resistance in $\mathrm{Eq} .6$, and is given by $F=\left(D_{c} \mathrm{C}^{\circ} \mathrm{a}_{\mathrm{C}}\right) / \mathrm{L}$, where $\mathrm{D}_{c}$ is the diffusion coefficient of carbon in alpha iron, $\mathrm{C}^{\circ}$ is the graphite solubility in $\alpha-\mathrm{Fe}$, and $\mathrm{L}$ is the membrane thickness. The calculated limiting curve, with the flux given in FID units, is $F=6.9 \times 10^{4} \mathrm{a}_{\mathrm{c}}$.
} 
of carbon-solubility data and the thermodynamic and solubility data for $\mathrm{Na}_{2} \mathrm{C}_{2}, G$. K. Johnson and coworkers ${ }^{5}$ have concluded that disodium acetylide is the dominant species in sodium, even at high temperatures. (Although thermodynamically unstable as a separate species, $\mathrm{Na}_{2} \mathrm{C}_{2}$ is stable up to $\mathrm{a}_{\mathrm{c}}=$ 1 in sodium solutions.)

The equation describing the variation of the meter reading with carbon activity in the presence of acetylide in the sodium may be derived from the steady-state condition at the sodium-membrane interface, which is as follows:

$$
k^{\prime}{ }_{F}^{a} \mathrm{Na}_{2} \mathrm{C}_{2}=k_{R}\left(a_{C}^{s}\right)^{2}+k_{D}\left(a_{C}^{8}\right)
$$

where

$$
\begin{aligned}
& k_{F}^{\prime}=\text { rate constant for decomposition of the acetylide at the interface, } \\
& \mathrm{a}_{\mathrm{Na}_{2} \mathrm{C}_{2}}=\text { activity of the acetylide in the sodium, } \\
& \begin{aligned}
a_{c}^{s}= & \text { activity of carbon just inside the surface of the membrane at the } \\
& \text { sodium-membrane interface, }
\end{aligned} \\
& \begin{aligned}
& k_{R}= \text { rate constant for recombination of carbon at the interface to form } \\
& \text { acetylide, }
\end{aligned} \\
& k_{D}=\text { combined constants for diffusion of carbon through the membrane } \\
& \text { and decarburization at the interior of the membrane. }
\end{aligned}
$$

The dimensions chosen for $k_{\mathrm{F}}^{\prime}, \mathrm{k}_{\mathrm{R}}$, and $\mathrm{k}_{\mathrm{D}}$ are $\mu \mathrm{g} \mathrm{c} /\left(\mathrm{cm}^{2}\right)(\mathrm{min})$. Thus, Eq. 7 expresses the carbon flux balance at the sodium-membrane interface.

The tab-equilibration method measures the carbon activity, $a_{c}$, in the sodium rather than the disodium acetylide activity. This carbon activity can be related to the disodium acetylide activity through the equilibrium constant, $K$, for the reaction $\mathrm{Na}_{2} \mathrm{C}_{2} \underset{2}{ } 2 \mathrm{Na}+2 \mathrm{C}$ as follows:

$$
a_{c}=\left(K \begin{array}{lll}
K a_{2} C_{2} & 1 / 2
\end{array}\right.
$$

On defining $k_{F}$ as $k_{F}^{\prime} K^{-1}$, Eq. 7 then becomes

$$
k_{F}\left(a_{c}\right)^{2}=k_{R}\left(a_{c}^{s}\right)^{2}+k_{D}\left(a_{c}^{s}\right) \text {. }
$$

From the manner in. which the constants are defined, $k_{F}$ is equal to $k_{R}$, and both will be represented by $k$. The carbon flux, $F$, which is equal to $k_{D} a_{C}^{S}$, can then be expressed in terms of $a_{C}$ (after substitution of $F / k_{D}$ for $a_{C}^{S}$ in Eq. 9 and solution of the resulting quadratic equation) as follows:

$$
F=\frac{\left(k_{D}\right)^{2}}{2 k}\left[\sqrt{1+\left(\frac{2 k_{c}{ }_{c}}{k_{D}}\right)^{2}}-1\right]
$$


Equation 10 reduces to $F=k\left(a_{C}^{2}\right)$ at low activities (acetylide control) and to $F=k_{D^{a}}$ at high activities (diffusion control) in accord with observation.

Equation 10 was fit to the UNC meter data in Fig. 8 after converting the FID readings to carbon fluxes. [Experiments with $\mathrm{CO}$ and $\mathrm{CH}_{4}$ calibration gases established that an FID unit corresponded to a flux through the iron membrane of $2.11 \times 10^{-5} \mathrm{\mu g} \mathrm{C/}\left(\mathrm{cm}^{2}\right)$ (min).] The resulting equation is as follows :

$$
F=0.0405\left(\sqrt{1+865 a_{c}^{2}}-1\right) \mu g c /\left(\mathrm{cm}^{2}\right) \text { (min). }
$$

Equation 11, with the flux converted back to FID units, is seen to fit the experimental data in Fig. 8 quite well. ${ }^{*}$ The values of $k_{D}$ and $k$ calculated from Eqs. 10 and 11 are 1.19 and $20.8 \mu \mathrm{g} \mathrm{C} /\left(\mathrm{cm}^{2}\right)$ (min), respectively. Thus $k$, the rate constant for transfer of acetylide to the iron membrane, is only 17.5 times as great as $k_{D}$, the combined constants for diffusion of carbon and decarburization at the interior of the membrane. The value for $k$ would have to be about 200 times as great as $k_{\mathrm{D}}$ for the meter calibration curves to be linear over the activity range studied here.

As was noted in the discussion of the effect of $\left(R_{1}+R_{4}\right)$ on the diffusion-meter flux (Eq. 6), carbon transport out of the sodium into the meter is promoted at a given carbon activity by increased stirring speed. Stirring speed was also found to be of importance in determining carburization rates of stainless steels (see Section III-D); therefore, this effect was examined further by varying the speed of the stirrer in pot experiments of the type shown in Fig. 2. At a fixed carbon activity, the effect of increasing the stirring speed over the range from zero to $1000 \mathrm{rpm}$ is to increase the flux of carbon through the meters by as much as a factor of two; these data are shown in Fig. 9. The bottom curve in the figure was measured in a Type 304 stainless steel pot; the others were measured during experiments in Type 200 nickel pots.

The rapid response of the high-area meter made it convenient to obtain on-line measurements of the curves given in Fig. 9 for this meter. These measurements were made by changing the stirring speed and allowing the meter reading to stabilize between each change in speed. An example of this type of measurement is shown in Fig. 10. The 5-min delay in response of the meter to a step change in stirring speed is the sum of the 1-min response time of the 5-mil iron membrane and the 4-min time required for the gas to flow from the meter membrane to the FID. The magnitude of the changes in FID readings with stirring speed was independent of the order in which the readings were taken, and the meter returned to its initial reading when the stirring speed was reset to its initial value. This suggests that the carbon activity in the sodium remained constant during measurement of the high-area-meter curves shown in Fig. 9. Carbon activities given with these curves are taken from the calibration curve in Fig. 8 .

\footnotetext{
${ }^{*}$ At the lowest-activities, background becomes a significant fraction of the FID reading. The poor fit below $a_{c}=10^{-2}$ may be due to inaccurate background correction.
} 


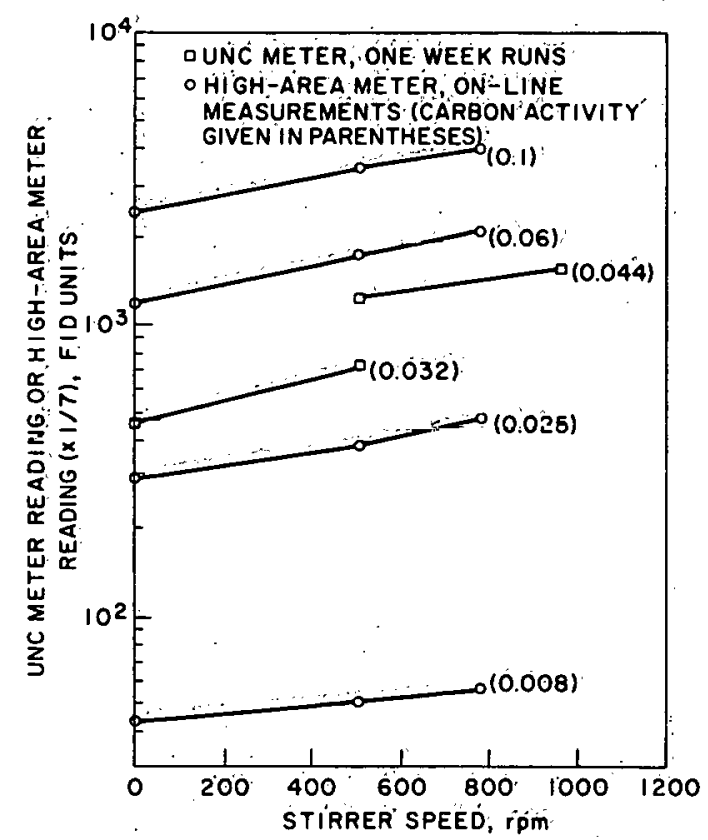

Fig. 9. Effect of Stirrer Speed on Carbon Flux Through the Diffusion-Type Carbon Meters. (Meter reading. in FID units is proportional to carbon flux:)

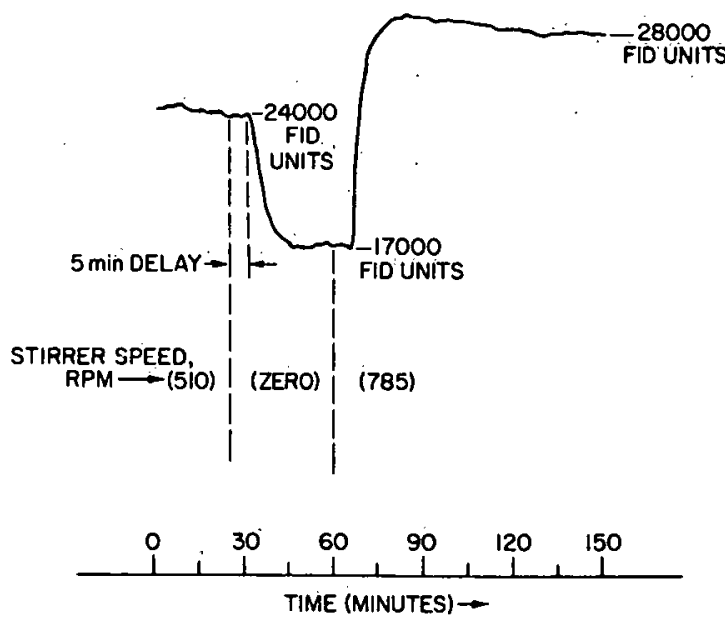

Fig. 10. High-area Diffusion Meter Reading: Measurement of Stirrer-speed Effect: 
The UNC-meter curves in Fig. 9 were determined in four week-long experiments in which the carbon activity was directly measured with $\mathrm{Fe}-8$ wt $\% \mathrm{Ni}$ and $\mathrm{Fe}-12$ wt \% Mn tabs. Two of these experiments (14 and 19 in Table III) were at an activity of about 0.044 , and two (15 and 16 in Table III), were at an activity of about 0.032. The near-parallelism of these UNC-meter curves and the high-area-meter curves confirms that the stirring speed effect observed on-line with the high-area meter is not simply a transient. It should be noted that the diffusion meter acts as a sink for carbon and that the flux of carbon from the sodium into this sink decreases with decreasing stirring speed. If the carbon activity in the sodium is to remain fixed, there must be a corresponding decrease in carbon flux into the sodium from the carbon source, $i . e$. , from the nickel or stainless steel pot. Therefore, relatively stagnant layers of sodium at bounding surfaces significantly limit carbon transport.

\section{Response of Stainless Steels to Carbon in Sodium}

Shiels and Bagnall 17 of Westinghouse Advanced Reactors Division (WARD) have employed Type 304 stainless steel of 3 -mil thickness as monitor tabs in their sodium loops, and have compared the carbon concentration in these monitor tabs, exposed at $704^{\circ} \mathrm{C}$, with the carbon concentration in other simultaneously exposed alloys, such as Type 321 stainless steel. The sodium loops at WARD were equipped with carbon sources (carbon contained within heated iron capsules) to permit carburization of steel specimens to carbon concentrations of as high as $6000 \mathrm{ppm} \mathrm{C}$ in a one-week run. With the carbon sources turned off; the Type 304 stainless steel, initially at $340 \mathrm{ppm} \mathrm{C}$, could be decarburized to as little as $25 \mathrm{ppm}$ C.

The ANL pot-type experiments with the stainless steel tabs provided another method of studying about the same range of carbon concentrations as those in the WARD work. However, our work with the stainless steels was devoted to comparing the responses of the stainless steel tabs and those of the activity-measuring tabs, $\mathrm{Fe}-8 \mathrm{wt} \% \mathrm{Ni}$ and $\mathrm{Fe}-12 \mathrm{wt} \% \mathrm{Mn}$, to carbon in sodium. In these experiments, carburization data were obtained for both Types 304 and 321 stainless steel. Only the Type 304 stainless steel results will be considered in detail; the response of the Type 321 stainless steel, shown in. Fig. 11, may be interpreted simply as the sum of the Type 304 stainless steel response (curve $B$ ) and the response of carbide-forming additives, such as $0.48 \% \mathrm{Ti}$, present in Type 321 stainless steel (curve A). (Note that the high slope of curve $A$ is as expected, in view of the measured response of carbide-forming elements to carbon in sodium, shown in Fig. 7.) The intercomparison of the carbon concentration in the two steels, curve $C$ in Fig. 11, is in good agreement with the loop-exposure data of Shiels and Bagna11. 18 .

The data from Table III for experiments that included both stainless steel and activity-measurement tabs are presented in Fig. 12. The diffusiontype-carbon-meter curves (from Figs. 8 and 9) are included to show the close parallel in response of the diffusion meters and Type 304 stainless steel to carbon in sodium. Note that this parallel extends to the response resulting from changes in sodium turbulence. According to the analysis of the diffusion-meter response presented above, the carbon flux in the low-activity region is controlled to a great extent by disodium acetylide. The parallel response of Type 304 stainless steel suggests that the carburization of the 


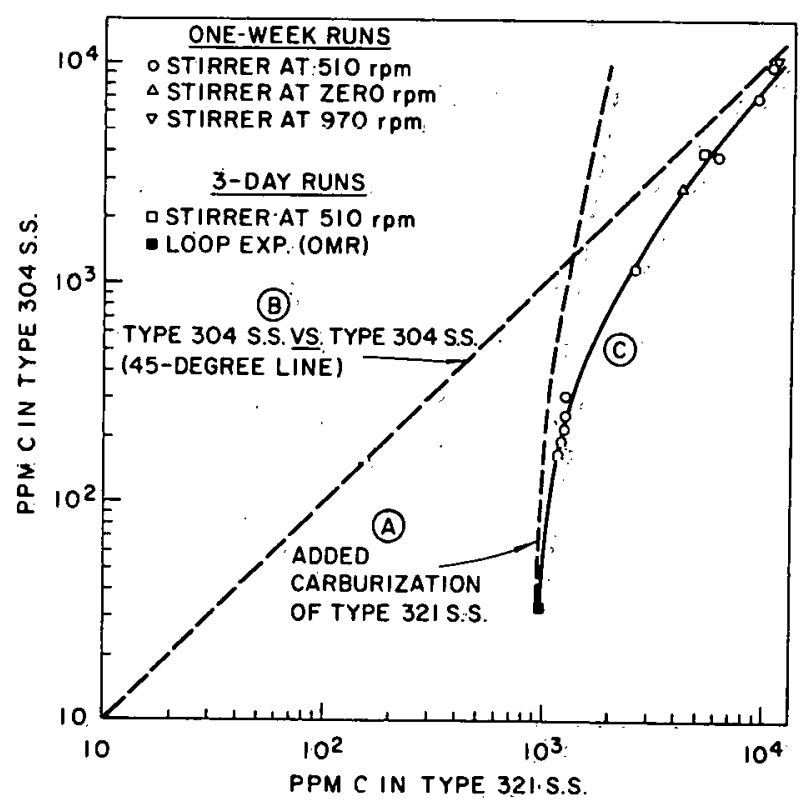

Fig. 11. Comparison of Carbon Concentration in Types 304 and 321 Stainless Steel after their Simultaneous Exposure to $700^{\circ} \mathrm{C}$ Sodium. (Curve A obtained by subtraction of Curve B from. curve $C$, the curve drawn through the data.)

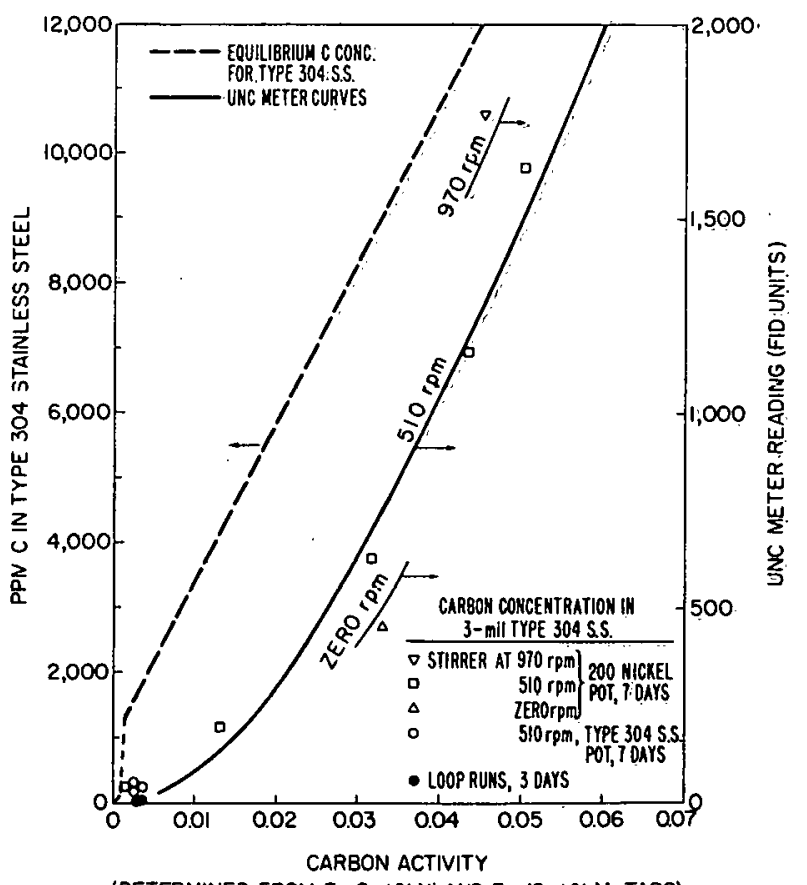

(DETERMINED FROM Fe-8wt \%Ni AND Fe-12wt \% Mn TABS)

Fig. 12. Comparison of Response of Type 304 Stainless Steel Tabs and Diffusion-type Carbon Meters in $700^{\circ} \mathrm{C}$ Sodium.

(Equilibrium carbon concentration in stainless steel estimated from data of Tuma et al. ${ }^{21}$. The UNC meter. curves are a combination of the curves given in Figs. 8 and 9.) 
steel is also controlled by disodium acetylide. It is evident from the parallel response that the variation of the diffusion-meter reading with carbon concentration in the stainless steel is nearly linear and independent of stirring speed, thereby making the UNC meter an excellent tool for measuring carburization conditions in sodium systems. Similar linear correlations have been observed by other investigators; 1919 our study suggests that the linearity is the result of rate limitations imposed by the sodium. Clearly, attempts to calculate carburization rates of stainless steels should take into account the effect of limitations imposed by the rate of reaction of disodium acetylide and by sodium turbulence, as observed in this work.

The calculated time for equilibration ( $99.95 \%$ saturation) of 3-mil Type 304 stainless steel, based on the published diffusion coefficient of carbon, 20 is only one day. However, the evident sensitivity of the steel carburization to stirring speed (Fig. 12) is an indication that, at higher carbon concentrations in the steel, the steel was not equilibrated after a one-week exposure. Through post-exposure optical microscopic examination of cross sections of the 3-mil tabs, the depth of heavy grain-boundary carbide precipitation was found to be approximately one mil. The long time required for equilibration at high carbon concentration is due not only to the kinetic limitations at the sodium/steel interface, but also to extensive carbide precipitation within the steel, in combination with a low carbon solubility (about $50 \mathrm{ppm} \mathrm{C}$ at $700^{\circ} \mathrm{C}$ in Type 304 stainless steel ${ }^{2 l}$ ) that limits carbon permeation. Competition from an immobilizing reaction, such as carbide formation, is known to slow the diffusion process. 22

The similar response of the stainless steel tabs and diffusion meters to carbon in sodium (Fig. 12) is made possible by the fact that neither is at equilibrium. However, nonequilibrium for the diffusion meters consists of a rapidly achieved steady state in which the carbon flux remains constant with time. The carbon flux into the stainless steel, on the other hand, is not fixed, but varies with time. The difference in response of the diffusion meter and stainless steel is revealed by varying the exposure time.

In conformance with stainless steel-tab usage at WARD, we employed a seven-day exposure in most of our tab experiments. However, one of the highactivity experiments was terminated after three-days (Expt. 18 in Table III). The carbon-concentration increase in the steel in this run, when multiplied by $(7 / 3)^{1 / 2}$, falls near the curve of carbon-concentration increase $v s$. diffusion-meter reading from the seven-day experiments (see Fig. 13). This indicates that the thickness of the carbide-precipitation zone in the steel grows parabolically with time. This type of parabolic relationship is characteristic of diffusion-controlled growth of a precipitate layer. We believe that the similar $a_{c}^{2}$ dependence observed for the meter and stainless steel (Fig. 12) arises primarily from control of their surface carbon concentration by disodium acetylide reaction at the surface; within the stainless steel and meter membrane, the carbon flux obeys the normal diffusion laws.

The time-averaged carbon flux into the stainless-steel tabs and the diffusion-meter membrane is nearly the same in a one-week run in spite of the difference in their time dependency. For example, at a carbon activity of 0.05 and stirrer speed of $510 \mathrm{rpm}$, the Type 304 stainless steel removed about $290 \mu \mathrm{g} \mathrm{C} / \mathrm{cm}^{2}$ of surface area from the sodium during the one-week run, whereas the UNC meter removed about $320 \mu \mathrm{g} \mathrm{C} / \mathrm{cm}^{2}$. Likewise, at a higher stirrer 


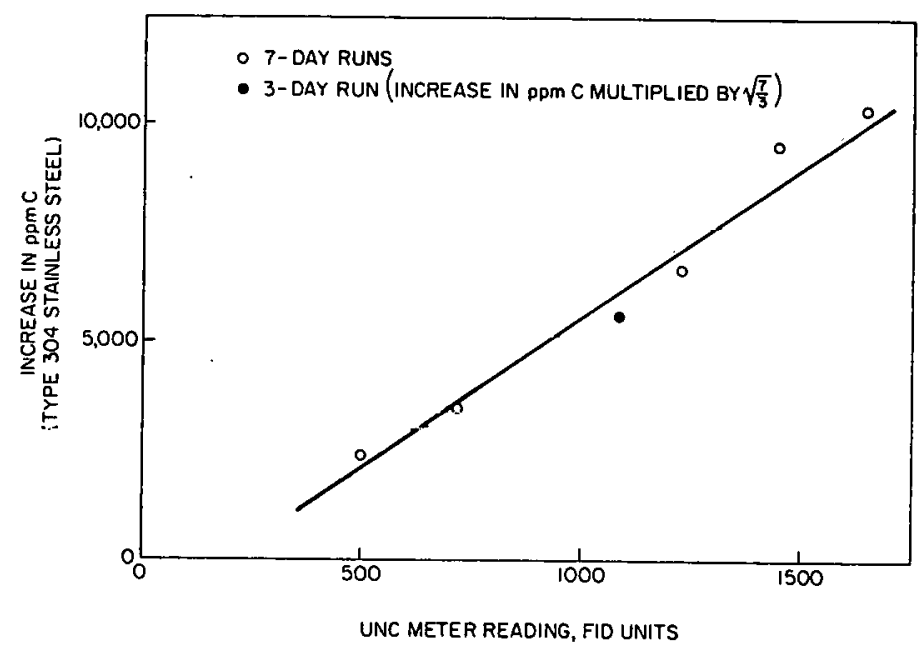

Fig. 13. Approximately Linear Relationship Between Type 304 Stainless Steel Carburization and UNC Meter Reading. [Carbide-layer thickness in steel increases parabolically with time (see text).]

speed, $785 \mathrm{rpm}$, and at a carbon activity of 0.05 , the estimated removals by the Type 304 stainless steel and the high-area meter were about $400 \mu \mathrm{g} \mathrm{C} / \mathrm{cm}^{2}$ and $450 \mu \mathrm{g} \mathrm{C} / \mathrm{cm}^{2}$, respectively. Since a one-week exposure leads to an average carbon flux that is nearly equal for the stainless steel tabs and diffusion meters, the nearly equal control of their response by acetylide, as reflected in the parallel behavior shown in Fig: 12, is perhaps not too surprising.

Shiels and Bagnal1 18 of WARD have shown that under decarburizing conditions, the 3-mil Type 304 stainless steel is equilibrated within three days in $700^{\circ} \mathrm{C}$ sodium (as expected in the absence of heavy carbide precipitation). Consequently, in the seven-day and three-day experiments in Fig. 12 that were done in the Type 304 stainless steel pot and in the sodium loops (all of which gave rise to decarburization of the steel), the tabs are essentially at equilibrium with respect to carbon. No attempt was made; therefore, to correlate these data with the UNC-meter curves, which give a measure of transport rates rather than equilibrium. * Although these stainless steel equilibrations in sodium at low carbon activities are more rapid than equilibrations in sodium at high carbon activities, they are still slower than expected on the basis of diffusion coefficients determined by conventional techniques. The carbon diffusion coefficient in Type 304 stainless steel at $700^{\circ} \mathrm{C}$ calculated from sodium-exposure runs in which the steel decarburized, 18,25 is at least an order of magnitude smaller than the coefficient obtained in:more conventional experiments. It has been suggested ${ }^{2} 3$ that

म

Even at high carbon concentrations; the stainless steel must eventually reach equilibrium with carbon, after which its carbon concentration will no longer depend on the kinetics of processes occurring in the sodium. The similarities in behavior of the steel and UNC meter will then disappear. 
this difference may be due to failure to account for a rate-controlling process at the sodium-steel interface or a rate process controlled by dissolution of carbides. The limitation imposed by disodium acetylide, discussed above, is an example of such a rate-controlling process operating at the sodium-steel interface.

An equilibrium curve for carbon in Type 304 stainless steel can be estimated from the detailed gas-equilibration studies of Tuma and coworkers, ${ }^{21}$ who measured the equilibrium curves at higher temperatures (ranging from $950^{\circ} \mathrm{C}$ to $1200^{\circ} \mathrm{C}$ ). Approximate boundaries for the austenite and austenite/carbide phases and the slope of the curves of carbon activity $v s$. concentration throughout these regions can be estimated from their study. The resulting estimated equilbrium curve is compared in Fig. 12 with our data for partially carburized stainless steel tabs (Type 200 nickel-pot runs) and for equilibrated tabs (Type 304 stainless steel-pot and sodium-loop runs).

In the curves obtained by Tuma et $a l^{21}$ at high temperatures, activity plateaus (i.e., a sharp increase in carbon concentration with only a small increase in activity) were seen that correspond to the onset of carbide precipitation. The estimated position of this plateau at $700^{\circ} \mathrm{C}$ is at an activity of about 0.001 (see Fig. 12). However, Campbell and Tyzack ${ }^{4}$ have calculated from thermodynamic data that the onset of carbide precipitation may occur at a carbon activity as high as 0.005 . An apparent difference in decarburization behavior of the stainless steel tabs in the Type 304 stainless steel-pot runs and the sodium-loop runs may be due to an activity plateau for the Type 304 stainless steel occurring at $a_{c} \cong 0.003$. It was found that exposure in the stainless steel pot gave a carbon concentration of 200 to $300 \mathrm{ppm} \mathrm{C}$ in the Type 304 stainless steel tabs and exposure in the loops gave a carbon concentration of only 30 to $40 \mathrm{ppm} \mathrm{C}$, although the carbon activity in the sodium, as medsuied by Fo-8 wt \% Ni and Fe-12 wt \% $\mathrm{Mn}$, in both cases was about 0.003 . In the case of the Type 304 stainless steel-pot runs, the Type 304 stainless steel tabs equilibrate (by carbon transport through the sodium) with the pot walls, which are at the same temperature as the tabs and which are expected to have a carbon concentration in the same range as that observed in the equilibrated tabs (200-300 ppm C). This differs from the situation in nonisothermal loops; in these systems, the carbon activity has been observed to be controlled by stainless steel surfaces held at a temperature somewhat lower than the maximum loop temperature. 25 If the carbon activity of the sodium in the loop is controlled by stainless steel surfaces at a temperature less than $700^{\circ} \mathrm{C}$ (the maximum loop temperature during these runs), the carbon activity of the sodium may be low enough to decarburize the stainless steel tabs located in the $700^{\circ} \mathrm{C}$ section to a carbon concentration (about $50 \mathrm{ppm} \mathrm{C}$ ) that corresponds roughly to the lower end of the activity plateau. This decarburization can proceed with only a small decrease in the carbon activity below a value of 0.003 , if an activity plateau exists at 0.003 . The activity decrease would be difficult to detect with the $\mathrm{Fe}-8$ wt \% $\mathrm{Ni}$ and $\mathrm{Fe}-12$ wt \%. Mn tabs, whose carbon concentrations at an activity of 0.003 are only 12 and $40 \mathrm{ppm}$, respectively. (The uncertainty in the carbon analysis is about $15 \%$ at a carbon concentration of $40 \mathrm{ppm}$. )

The above suggestion as to the cause of the different levels of carbon in the Type 304 stainless steel at essentially the same carbon activity (about $3 \times 10^{-3}$ ) requires experimental verification. In particular, accurate 
measurements are needed to establish a curve of equilibrium carbon concentrations vs. activities for Type 304 stainless steel at low carbon concentrations. These measurements can be done in part through inclusion of both $\mathrm{Fe}-12$ wt \% Mn and Type 304 stainless steel tabs during routine measurements of the carbon activity in sodium loops.

It should be noted that other explanations might be advanced for the difference in carbon contents of Type 304 stainless steel tabs at low carbon activities. For example, it has been noted ${ }^{l}$ that high concentrations of strong carbide-forming impurities in alloys such as $\mathrm{Fe}-8 \mathrm{wt} \% \mathrm{Ni}$ would lead to insensitivity at low carbon activities. However, the $\mathrm{Fe}-8$ wt $\% \mathrm{Ni}$ and $\mathrm{Fe}-12$ wt \% $\mathrm{Mn}$ used in this work had low connentrations of strong carbide formers such as $T 1, V$, and Mo, especially in comparison with the concentration of these elements in the Type 304 stainless steel (see Table II). Therefore, it is unlikely that insensitivity of the $\mathrm{Fe}-8$ wt \% $\mathrm{Ni}$ and $\mathrm{Fe}-12$ wt \% $\mathrm{Mn}$ tabs was a problem.

At this time; the use of Type 304 stainless steel for measurements of carbon activity is not recommended because of the complicated nature of the steel's response at high carbon activities and the uncertain nature of the equilibrium curve at low activities. Conversely, carbon-activity measurements. can now be correlated only roughly with carbon concentrations in steels; an activity measurement does not, for example, give sufficient information to predict carburization rates. If a carburization rate is desired for a steel in a sodium system, the logical approach would be to expose the steel and measure the rate directly; $\mathrm{Fe}-12$ wt $\% \mathrm{Mn}$ tabs could be employed as carbon activity monitors and as an aid in interpreting the carburization data in these studies.

\section{E. Response of Electrochemical Meters to Carbon in Sodium}

Two different electrochemical meters were tested for the determination of carbon in sodium. One of the meters was developed at Brookhaven National Laboratory (BNL meter ${ }^{7}$ ) and the other at Argonne National Laboratory (ANL meter ${ }^{8}$ ). The meters are shown in Figs. 3 and 4 and their operation is described in Section II. The data from experiments with these meters are included in Table III. These data indicate that only the ANL meter responds we11 to low carbon activities.

Two problems were encountered with the BNL meter. As noted by Salzano and coworkers, 7 the meter tends to short out after some hundreds of hours of use because of the growth of iron whiskers on the graphite reference electrode: The same problem was encountered in our tests; the BNL meter shorted to zero $\mathrm{mV}$ during the fourth run (Expt. 28, Table III). Meter operation was restored by the recommended procedure of breaking off the whiskers. The other problem was that the meter did not respond as expected at low carbon activities. The data from experiments with the BNL meter are compared in Fig. 14 with the curve that the meter is expected to follow. ${ }^{7}$ The measured emf is seen to be less than expected, and it approaches a limit in the region of lower carbon activities (the region of greatest interest).

It is interesting to note that none of the experiments with the BNL meter in the Type 304 stainless steel assembly resulted in carbon activity. 


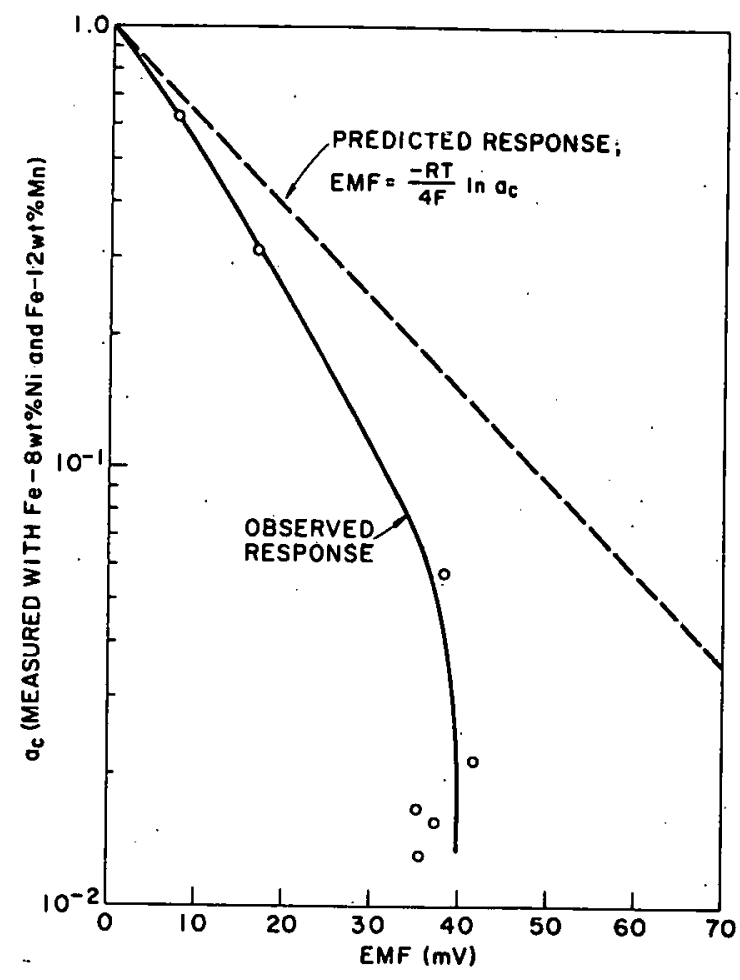

Fig. 14. Comparison of (1) Measured Response of BNL Meter to Carbon in $700^{\circ} \mathrm{C}$ Sodium; (2) Predicted Response from Ref. 7.

determinations by tabs of less than $10^{-2}$, whereas tests with either the other meters or with tabs alone routinely gave activities of $6 \times 10^{-3}$ or less in the assembly. This suggests that carbon is being transported from the graphite reference electrode of the meter, through the iron membrane, and into the sodium. Such a process could raise the steady-state carbon activity of the iron membrane above the carbon activity in the sodium, and may be the cause of the poor response of the meter. Tests of this meter were terminated because it was believed that the problems encountered were of a fundamental nature associated with the well-known corrosive action of carbonate melts. 26

The theoretical potential of the ANL electrochemical meter is calculated (see Ref. 8) from the free energies of formation of $\mathrm{SnO}_{2}^{2} 7$ and of $\mathrm{CO}$ and $\mathrm{Co}_{2} \cdot{ }^{28}$ The result of this calculation is as follows:

where

$$
\operatorname{Emf}(\mathrm{mV})=49.6-96.62 \log \left[0.5\left(1+\frac{4 \mathrm{P}}{\mathrm{Ka}}\right)^{1 / 2}-0.5\right]
$$

$$
\begin{aligned}
& P=2 \text { Torr }=2.63 \times 10^{-3} \mathrm{~atm}, \\
& \mathrm{~K}=\text { the equilibrium constant for the reaction } \\
& \mathrm{C}+\mathrm{CO}_{2} \underset{\leftarrow}{ } 2 \mathrm{CO} \cdot\left(\mathrm{K}=0.8897 \text { at } 700^{\circ} \mathrm{C}^{29}\right), \\
& a_{c}=\text { the chemical activity of carbon in the sodium. }
\end{aligned}
$$


The measured potentials (Expts. 23 and 4I, Table III) are compared in Table VI with the theoretical potentials that were calculated from Eq. 12 and from carbon activities determined by analysis of the $\mathrm{Fe}-8$ wt $\% \mathrm{Ni}$ and $\mathrm{Fe}-12$ wt \% Mn tabs exposed during the runs. [A thermopotential correction of 6.7 $\mathrm{mV}$ was added to these calculated theoretical potentials to correct for the iron-tungsten thermopotential (see Fig. 4 and Ref. 8).]. The agreement between the measured and calculated potentials is seen to be very good.

TABLE VI. Experiments with ANL Electrochemical Carbon Meter ${ }^{a}$

\begin{tabular}{lcccc}
\hline & $\begin{array}{c}\text { Carbon Activity } \\
\text { (Tab Measurements) }\end{array}$ & \multicolumn{2}{c}{ Emt, mV } \\
\hline Type 200 Nickel & 0.137 & 211 & 219 \\
Type 304 Stainless Steel & 0.005 & 93 & 93 \\
\hline
\end{tabular}

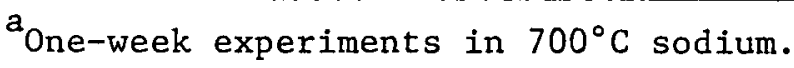

These preliminary tests suggest that the ANL ineter is capable of sensing the carbon actlvity in low-activity stainless steel systems; in the experiment with the stainless steel pot, the activity $(0.005)$ is within a factor of three of the lowest activity we have observed in such systems. During the experiments with this meter, the gas space was occasionally pumped out and refilled to 2 Torr with the $\mathrm{CO}(66 \%)$ and $\mathrm{CO}_{2}(34 \%)$ gas mixture. The meter potential returned to its steady-state value within about $1 / 2 \mathrm{hr}$. This indicates that equilibration of the gas mixture is rapid; the meter will be useful in carbon-activity studies requiring a fast response.

It is necessary to operate the ANL electrochemical meter at a totr. pressure lower than 2 Torr in very low carbon-activity systems. (The relatively high pressure, 2 Torr, used in the meler during our tests permitted accurate pressure measurements.) At a pressure of 2 Torr and at carbon activities less than $3 \times 10^{-3}$, the $\mathrm{CO} / \mathrm{CO}_{2}$ gas mixture will oxidize the iron membrane (forming wustite), and the partial pressure of oxygen in the gas mixture will then remain constant at a level set by the wustite-iron equilibrium. Under these conditions, the meter will not respond to the carbon activity. The lower operating limit for the meter is proportional to the total pressure. For example, at a pressure of about $2 / 3$ Torr, the meter is expected to operate satisfactorily at carbon activities as low as $1 \times 10^{-3}$.

\section{F. Response of ANL Pressure-type Carbon Meter to Carbon in Sodium}

The ANL pressure-type carbon meter was developed in this study to meet the need for a simple on-line monitor for use in sodium loops and reactors. The meter's operation and construction, outlined in Section II and Fig. 5., is relatively uncomplicated. In addition, the meter develops a conveniently high pressure in systems having a low carbon activity, and is expected to be substantially free from interference. For example, during normal loop operation, hydrogen (and water in equilibrium with the hydrogen and wustite) will be at pressures of the order of $10^{-3}$ of the $\mathrm{CO}+\mathrm{CO}_{2}$ pressure in the meter, ${ }^{29}$ and will not interfere with the pressure measurement. Also, at the low nitrogen levels existing in the argon cover gas of sodium loops (normally less than $100 \mathrm{ppm}$ ); little interference from nitrogen or its oxides is anticipated. 
The pressure-type meter employs a wustite $\left(\mathrm{Fe}_{0.9470)}\right.$ layer on its interior surface as an oxygen source for generation of $\mathrm{CO}$ and $\mathrm{CO}_{2}$ within the meter. (It should be noted that this technique of supplying oxygen has been employed in a recently developed diffusion-type carbon meter ${ }^{30}$ in which the CO flux is measured, after conversion of the $C O$ to methane, by flame ionization detection. The response of this diffusion meter should be similar to the UNC-meter response discussed above.) The equilibria governing the reaction of wustite with carbon are as follows:

$$
\begin{aligned}
& \mathrm{Fe}_{0.9470}+\mathrm{C} \rightarrow 0.947 \mathrm{Fe}+\mathrm{CO} ; \mathrm{K}=\frac{{ }^{\mathrm{P}_{\mathrm{CO}}}}{\mathrm{a}_{\mathrm{C}}} \\
& 2 \mathrm{Fe}_{0.9470+\mathrm{C}} \rightarrow 1.894 \mathrm{Fe}+\mathrm{CO}_{2} ; \mathrm{K}=\frac{{ }^{\mathrm{PCO}_{2}}}{\mathrm{a}_{\mathrm{C}}}
\end{aligned}
$$

These equilibria show that both the $\mathrm{CO}$ and $\mathrm{CO}_{2}$ pressures (and, consequently, their sum) are proportional to carbon activity. From the equilibrium constants at $700^{\circ} \mathrm{C}$ for the above reactions, ${ }^{31}$ the following equations were calculated:

$$
\begin{aligned}
& \frac{\mathrm{P}_{\mathrm{CO}_{2}}}{\mathrm{P}_{\mathrm{CO}}}=0.578 \\
& \mathrm{P}_{\mathrm{CO}}+\mathrm{P}_{\mathrm{CO}_{2}}=743 \mathrm{a}_{\mathrm{c}}
\end{aligned}
$$

where $\mathrm{P}_{\mathrm{CO}}$ and $\dot{\mathrm{P}}_{\mathrm{CO}_{2}}$ are given in Torr.

The conslants in these equations are subject to considerable uncertainty because they rely on small differences between large free energies of formation, and the free energy of formation of wustite is known only to within 200 calories. This uncertainty of 200 calories leads to a $15 \%$ uncertainty in the constant in Eq. 14. (The free energies of formation of the oxides of carbon are known accurately enough to ignore their contribution to the uncertainty.) The value of the free energy of formation of wustite used in calculating Eqs. 13 and 14 is $-48.2 \mathrm{kcal} / \mathrm{mol}$ at $700^{\circ} \mathrm{C}$. $^{31}$ This value was obtained by averaging five independent calorimetric or reduction-equilibria methods, including $\mathrm{CO}$ reduction equilibria. (It should be noted, however, that electrochemical cell measurements have yielded somewhat higher values of $-48.0 \mathrm{kcal} / \mathrm{mol}^{32}$ and $-47.9 \mathrm{kcal} / \mathrm{mol} .33$ We prefer the CO reduction-equilibria values because the meter is based on this equilibrium.)

The measured $\mathrm{CO}+\mathrm{CO}_{2}$ pressures (Expts. 24 and 42, Table III) are compared in Table VII with the theoretical pressures calculated from Eq. 14 and from carbon activities determined by analysis of the Fe-8 wt \% $\mathrm{Ni}$ and $\mathrm{Fe}-12$ wt \% Mn tabs exposed 'during the runs.

The theoretical pressures, although subject to some uncertainty as noted above, are seen to be in good agreement with the measured pressures. Of more significance is the high precision obtainable at low carbon activities with the pressure meter; a pressure change of $1 \%$ is readily detected on-line. Successive Fe-12 wt \% Mn tab determinations of carbon activity at a low activity, such as $5 \times 10^{-3}$, may disagree by as much as $15 \%$ because of 
TABLE VII. Experiments with ANL Pressure-type Carbon Meter ${ }^{a}$

\begin{tabular}{lcccc}
\hline & $\begin{array}{c}\text { Carbon Activity } \\
\text { (Tab Measurements) }\end{array}$ & (Measured) & (Theoretica1) \\
\hline Type 200 Nickel & 0.171 & 125.7 & 127.0 \\
Type 304 Stainless Steel & $6.04 \times 10^{-3}$ & 4.9 & 4.5 \\
\hline
\end{tabular}

${ }^{\mathrm{a}}$ One-week experiments in $700^{\circ} \mathrm{C}$ sodium.

uncertainties in analyses for carbon in the tabs at low rarbon activilles. Consequent1y, the prcssure meler represents a significant advance over tab methods in the measurement of low carbon activities.

Some development work is needed to improve the response time of the meter. In the high-carbon-activity experiment, for example, the meter required five days to reach its steady-state pressure, 125.7 Torr. In the lowactivity experiment, the pressure rose initially to 7 Torr in 30 hours, and then decreased slowly to 4.9 Torr by the sixth day of the seven-day run. In both runs, the initial rise in pressure was parabolic, and was probably limited chiefly by slow diffusion through the wustite layer. (The estimated equilibration time, assuming the rate-limiting step to be carbon diffusion in iron, is only two hours. Therefore, the equilibration is not expected to be slowed appreciably by diffusion in iron itself.)

It is believed that the equilibration time can be reduced by about a factor of ten by (1) increasing the surface-to-volume ratio of the iron capsule, and (2) decreasing the fraction of the gas in the meter that is at room

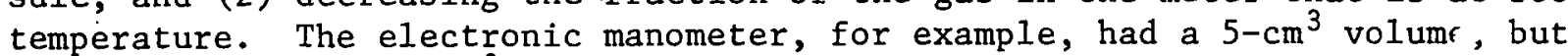
sensors having a $0.2-\mathrm{cm}^{3}$ volume are available. In the present design, only 15 at. \% of the gas is at $700^{\circ} \mathrm{C}$.

Following the calibration runs, the pressure meter was operated on the OMR sodium loop for a period of one month, after which the meter failed by developing a leak. (A more durable meter, with an iron membrane twice as thick as the original $10-\mathrm{mil}$ membrane, is being constructed for installation in a sodium 1oop.) During the one-month period of meter operation, the meter was held at $700^{\circ} \mathrm{C}$ in the equilibration section normally used for tab exposure; the main-1oop temperature was about $480^{\circ} \mathrm{C}$, and the temperature of the cold trap ${ }^{*}$ was occasionally varied in order to measure the effect of cold-trap temperature on carbon activity.

The initial week-1ong equilibration of the meter on OMR was similar to the Type 304 stainless steel-pot run; the pressure first rose to 3.3 Torr in $.14 \mathrm{hr}$, and then slowly decreased to 1.71 Torr, the value recorded during the sixth and seventh day. (The cold-trap temperature was $125^{\circ} \mathrm{C}$ during this run.) According to Eq. 14, a pressure of 1.71 Torr corresponds to a carbon activity of $2.3 \times 10^{-3}$. The cold-trap temperature was then raised to $208^{\circ} \mathrm{C}$ and the meter pressure rose (in about one day) to a steady-state pressure of 2.2 Torr. This pressure corresponds to a carbon activity of $2.9 \times 10^{-3}$. The small $(25 \%)$ increase in carbon activity on increasing the temperature of the

*The cold trap is normally used to control the impurities oxygen and hydrogen (see, for instance, refs. 29 and 34 ). 
cold trap from $125^{\circ} \mathrm{C}$ to $208^{\circ} \mathrm{C}$ contrasts sharply with the behavior of oxygen ${ }^{34}$ and hydrogen. 29 oxygen, for example, increases in concentration by a factor of approximately fifteen over the same temperature range. Tab-equilibration measurements in OMR, reported in Table III and conducted at a cold-trap temperature of $155^{\circ} \mathrm{C}$, led to carbon activities of $2.5 \times 10^{-3}, 2.9 \times 10^{-3}$, and $3.5 \times 10^{-3}$ (based on $\mathrm{Fe}-12$ wt $\% \mathrm{Mn}$ data). These values are in fair agreement with the above pressure-meter results.

A gradual decrease in the value of the steady-state pressure was noted in successive equilibrations during the one-month operation of the meter on OMR; a carbon activity as low as $1 \times 10^{-3}$ at a cold-trap temperature of $140^{\circ} \mathrm{C}$ was being recorded toward the end of the run. These lower activities may have been due to a real decrease in the carbon activity of the system with time, as the equilibration zone slowly decarburized during sustained operation at high temperature. Confirmation of this effect is needed, however, since the meter did eventually develop a sodium leak (leading to a pressure reading near zero). The more durable meter (being constructed) can be used to test further the effect of sustained operation of a highly nonlsothermal sodium system on the carbon activity. 
IV. CONCLUSIONS

In this study, the characteristics of two classes of sensors for carbon in $700^{\circ} \mathrm{C}$ sodium have been investigated. One class comprises the ANL meters and the $\mathrm{Fe}-12$ wt \% $\mathrm{Mn}$ and $\mathrm{Fe}-8$ wt \% Ni tabs; this class is useful for determining the chemical activity of carbon independent of kinetic factors. The other class, which includes Type 304 stainless steel tabs and the UNC diffusion-type carbon meter, gives a measure of the carbon flux and may be characterized as carburization sensors. They make it possible to detect the complicating factors that enter into carburization rates. Accurate studies of carburization-decarburization phenomena in sodium-steel systems will require simultaneous use of both classes of sensors.

Routine monitoring of the chemical activity of carbon in sodium loops is now possible through the use of either the Fe-12 wt \% Mn tab-equilibration method or the ANL carbon meters. These methods are far more sensitive than conventional methods of analysis of carbon in sodium.

\section{ACKNOWLEDGMENTS}

This work was supported by the USAEC Division of Reactor Development and Technology. The authors wish to thank W. Ruther, T. Kassner, K. Natesan, $\mathrm{J}$. McKee, H. Feder, and C. Luner for valuable discussions during this study, and $\mathrm{S}$. Skladzien for his aid in constructing and testing the pressure-type carbon meter. 


\section{REFERENCES}

1. K. Natesan and T. F. Kassner, Nuc1. Techno1. 19, 46 (1973).

2. C. Luner, Argonne National Laboratory, private communication (1971).

3. D. L. Smith, Nucl. Technol. 11, 115 (1971); D. L. Smith and R. H. Lee, ANL-7891 (1972).

4. RDT Standard F 3-40, Interim Methods for the Analysis of Sodium and Cover Gas, Div. of Reactor Development and Technology, USAEC (May

5. G. K. Johnson et al., J. Chem. Thermodyn. 5, 57 (1973).

6. J. M. McKee, W. A. Caplinger, and M. Kolodney, Nucl. Appl. 5, 236 (1968).

7. F. J. Salzano, L. Newman, and M. R. Hobdell, Nuc1. Technol. 10, 335 (1971).

8. W. Ruther, S. Skladzien, M. Roche, and J. Allen, Nuc1. Techno1. 21, 75 (1974).

9. J. Chipman, Met. Trans. 3, 55 (1972).

10. Tsuguyasu Wada, Harue Wada, J. F. Elliot, and J. Chipman, Met. Trans: $\underline{2}$, 2199 (1971). 11. Tsuguyasu Wada, Harue Wada, J. F. Elliot, and J. Chipman, Met. Trans. $\underline{3}$,
$1657(19972)$.

12. C. Bodsworth, I. M. Davidson, and D. Atkinson, Trans. Met. Soc. AIME 242, 1135 (1968).

13. Metals Handbook, prepared under the direction of the Metals Handbook Committee, American Chemical Society for Metals, Cleveland, Ohio (1948), p. 1251 .

14. R. M. Hudson, Trans. Met. Soc. AIME 227, 695 (1963).

15. S. Dushman, Scientific Foundations of Vacuum Technique, 2nd Ed., pp. 570-581, J. M. Lafferty, Ed., John Wiley and Sons, N. Y. (1962).

16. L. S. Darken and E. T. Turkdogan, Heterogeneous Kinetics at Elevated Temperatures, pp. 25-101, G. R. Belton and W. L. Worrel1, Eds., Plenum Press, N. Y. (1970).

17. S. Shiels and C. Bagnall, Components Materials Compatibility, WARD-4210 T1-3 (1971).

18. S. Shiels and C. Bagnall, Westinghouse Advanced Reactor Division (WARD), private communication (1972).

19. S. J. Rodgers and R. J. Shreve, MSAR-70-54 (1970). 
20. R. P. Agarwala et al., J. Nucl. Mater. 36, 41. (1970).

21. V. H. Tuma, P. Grobner, K. Lobl, BNWL-TR-72 (1972).

22. J. Crank, The Mathematics of Diffusion, pp. 121-122, Oxford University Press, London (1956).

23. D. W. Sandusky, J. S. Armijo, and W. J. Wagner, J. Nucl. Mater. 46, 225 (1973).

24. C. S. Campbell and C. Tyzack, Alkali Metal Coolants, Paper SM-85/19, IAEA, Vienna (1967).

23. P. Roy and G. P. Wozadlo, Nucl. Technol. 10, 307 (1971).

26. A. Borucka, Electrochim. Acta 13, 295 (1968).

27. T. N. Belford and C. B. Alcock, Trans. Faraday Soc. 61, 443 (1965).

28. T. H. Edsell and S. N. Flengas, Met. Trans. 3, 31 (1972).

29. D. R. Vissers, J. T. Holmes, L. G. Bartholme, P. A. Nelson, A Hydrogen Activity Meter for Liquid Sodium and Its Application to HydrogenSolubility Measurements (to be published).

30. R. C. Asher et al., Progress in the Development of Carbon Meters for Sodium-cooled Fast Reactors, BNES Conference on Liquid Alkali Metals, Nottingham Univ., Apr. 1973'

31. G. L. Humphrey, E. G. King, K. K. Kelley, Some Thermodynamic Vallies for Ferrous Oxide, Bureau of Mines Report of Investigations No. 4870 (June 1952).

32. R. A. Rapp, Trans. Met. Soc. AIME 227, 371 (1963).

33. G. G. Charette and S. N. Flengas, J. Electrochem. Soc. 115, 796 (1968).

34. J. M. McKee et aZ., Calibration Stability of Oxygen Meters for LMFBR Systems (to be published). 